\title{
Investigating the frequency and interannual variability in global above-cloud aerosol characteristics with CALIOP and OMI
}

\author{
R. Alfaro-Contreras ${ }^{1}$, J. Zhang ${ }^{1}$, J. R. Campbell ${ }^{2}$, and J. S. Reid ${ }^{2}$ \\ ${ }^{1}$ Department of Atmospheric Science, University of North Dakota, Grand Forks, ND, USA \\ ${ }^{2}$ Marine Meteorology Division, Naval Research Laboratory, Monterey, CA, USA \\ Correspondence to: J. Zhang (jzhang@atmos.und.edu)
}

Received: 12 January 2015 - Published in Atmos. Chem. Phys. Discuss.: 17 February 2015

Revised: 8 November 2015 - Accepted: 9 November 2015 - Published: 14 January 2016

\begin{abstract}
Seven and a half years (June 2006 to November 2013) of Cloud-Aerosol Lidar with Orthogonal Polarization (CALIOP) aerosol and cloud layer products are compared with collocated Ozone Monitoring Instrument (OMI) aerosol index (AI) data and Aqua Moderate Resolution Imaging Spectroradiometer (MODIS) cloud products in order to investigate variability in estimates of biannual and monthly above-cloud aerosol (ACA) events globally. The active- (CALIOP) and passive-based (OMI-MODIS) techniques have their advantages and caveats for ACA detection, and thus both are used to derive a thorough and robust comparison of daytime cloudy-sky ACA distribution and climatology. For the first time, baseline above-cloud aerosol optical depth (ACAOD) and AI thresholds are derived and examined $(\mathrm{AI}=1.0, \mathrm{ACAOD}=0.015)$ for each sensor. Both OMI-MODIS and CALIOP-based daytime spatial distributions of ACA events show similar patterns during both study periods (December-May) and (June-November). Divergence exists in some regions, however, such as Southeast Asia during June through November, where daytime cloudy-sky ACA frequencies of up to $10 \%$ are found from CALIOP yet are non-existent from the OMI-based method. Conversely, annual cloudy-sky ACA frequencies of 20$30 \%$ are reported over northern Africa from the OMI-based method yet are largely undetected by the CALIOP-based method. Using a collocated OMI-MODIS-CALIOP data set, our study suggests that the cloudy-sky ACA frequency differences between the OMI-MODIS- and CALIOP-based methods are mostly due to differences in cloud detection capability between MODIS and CALIOP as well as QA flags used. An increasing interannual variability of $\sim 0.3-0.4 \%$ per year (since 2009) in global monthly cloudy-sky ACA
\end{abstract}

daytime frequency of occurrence is found using the OMIMODIS-based method. Yet, CALIOP-based global daytime ACA frequencies exhibit a near-zero interannual variability. Further analysis suggests that the OMI-derived interannual variability in cloudy-sky ACA frequency may be affected by OMI row anomalies in later years. A few regions are found to have increasing slopes in interannual variability in cloudysky ACA frequency, including the Middle East and India. Regions with slightly negative slopes of the interannual variability in cloudy-sky ACA frequencies are found over South America and China, while remaining regions in the study show nearly zero change in ACA frequencies over time. The interannual variability in ACA frequency is not, however, statistically significant on both global and regional scales, given the relatively limited sample sizes. A longer data record of ACA events is needed in order to establish significant trends of ACA frequency regionally and globally.

\section{Introduction}

The above-cloud aerosol (ACA) phenomenon, wherein significant active-based backscatter and passive-based scattered solar radiances are induced by particles above what are predominately lower-tropospheric clouds, has gained an increased amount of attention from the scientific community (e.g., Haywood et al., 2004; Wilcox et al., 2009; Coddington et al., 2010; Devasthale and Thomas, 2011; Wilcox, 2012; Kacenelenbogen et al., 2014). In particular, whereas passivebased atmospheric retrievals are compromised by a binding inability to decouple aerosol, cloud, and atmospheric radiances in the ACA scenario, corresponding cloud property 
retrievals are uniquely biased (Wilcox et al., 2009; Meyer et al., 2013; Alfaro-Contreras et al., 2014; Li et al., 2014). ACA further perturbs regional radiation budgets by absorbing and reflecting radiation from the cloud layers underneath the unidentified aerosol particle layer (e.g., Haywood et al., 2004), which again must be accounted for when estimating global cloud and aerosol forcing budgets and regional semidirect impact on static stability and cloud feedback. Global oceans are covered with clouds nearly $70 \%$ of the time (e.g., Rossow and Schiffer, 1999), with almost non-existent corresponding ground-based verification data of ACA phenomena. This exacerbates the impact of ACA effects globally, limiting characterization of any quantitative impact and frequency of occurrence almost exclusively to satellite-based measurements.

ACA events are most effectively identified using activebased lidar measurements; this has been demonstrated using the Cloud-Aerosol Lidar with Orthogonal Polarization (CALIOP; Winker et al., 2010; Kacenelenbogen et al., 2014), one of the few such instruments presently in satellite orbit. CALIOP measures backscattered signals at the 532 and $1064 \mathrm{~nm}$ wavelengths, including segregated linearly parallel and orthogonal polarization backscatter states in the former channel. In particular, the active-profiling element is essential for decoupling aerosol and cloud scattering contributions in ACA events (Devasthale and Thomas, 2011). Utilizing 4 years of CALIOP level 2 data (Winker et al., 2009), Devasthale and Thomas (2011) evaluated seasonal and latitudinal patterns of ACA for liquid water cloud events. AlfaroContreras et al. (2014) describe seasonal frequencies in ACA over the southern Atlantic Ocean off the West African coastline as well as over the Gulf of Tonkin in Southeast Asia, where high ACA loading episodes were found during the summer and fall months and early spring months, respectively.

Whereas limited process studies have helped raise awareness of the ACA problem overall, year-to-year variability in global ACA frequency distribution has not yet been developed with CALIOP. Despite a nearly 8-year (2006-present) CALIOP data archive being available, one must take into consideration the fact that satellite lidar profiling is constrained presently to a single laser-illuminated curtain and roughly 16 daily orbits of the planet. Questions thus arise about the representativeness of CALIOP data sets for some climatological analyses, like ACA, given its temporal persistence and spatial extent (Devasthale and Thomas, 2011; Yu et al., 2012). Additionally, for CALIPSO-based ACA studies to be meaningful, the potential impacts of signal deterioration to CALIOP-derived aerosol optical depth (AOD) values need to be known. Despite the practical limitations of applying passive sensors for studying phenomena like ACA, the relatively wide field of view on passive imagers renders far greater data volume, which makes them more ideal options for a long-term study.
Ozone Monitoring Instrument (OMI) measurements have also been used for studying ACA events (e.g., Wilcox et al., 2009; Yu et al., 2012; Alfaro-Contreras et al., 2014). In particular, the OMI aerosol index (AI), computed using the difference between observed and calculated ultraviolet (UV) radiances (Torres et al., 2007), has been used to locate UV-absorbing aerosols suspended over bright cloud decks (e.g., Yu et al., 2012; Torres et al., 2012). This technique, originally used on the Total Ozone Mapping Spectrometer (TOMS), can only be used to detect UV-absorbing aerosols, such as biomass burning smoke and desert dust aerosols, and is sensitive to underneath cloud properties (e.g., Yu et al., 2012; Alfaro-Contreras et al., 2014). Further, and compared with CALIOP, OMI measurements represent a relatively large surface footprint of $13 \times 24 \mathrm{~km}$ at nadir, which limits cloud-clearing efficacies since footprints of this size are prone to sub-pixel cloud contamination (Torres et al., 2007). Collocated Moderate Resolution Imaging Spectroradiometer (MODIS) observations, however, as part of NASA's A-Train satellite constellation, which includes CALIOP (Stephens et al., 2002), can be utilized to distinguish and filter cloudy pixels/scenes within the OMI footprint.

Comparison of active- vs. passive-based sensors for evaluating the spatiotemporal coverage of ACA events, and for studying interannual variability in ACA occurrence on regional and global scales, represents a conservative means for conceptualizing the breadth of the problem. The goal of this work is, therefore, to compare and contrast distributions in global and regional ACA frequencies and their year-to-year variability using both CALIOP- and OMI- based approaches. Caveats to each approach are specifically identified, and thus qualified within the discussion so as to keep comparison as consistent and robust as possible. We highlight regions particularly susceptible to ACA occurrence, establishing a baseline for future ACA-induced biases in satellite cloud property retrievals overall.

\section{Data sets and methodology}

CALIOP level $25 \mathrm{~km}$ cloud and aerosol layer products (Winker et al., 2010) and OMI level 2 collection 3 UV aerosol products (OMAERUV; Torres et al., 2007) are paired with collection 5.1 Aqua MODIS cloud products (MYD06_L2; King et al., 1997) from June 2006 through November 2013. Aerosol Robotic Network (AERONET; Holben et al., 1998) level 2.0 version 2 cloud-screened data are also used to assist the analysis.

For identification of ACA, $5 \mathrm{~km}$ CALIOP $532 \mathrm{~nm}$ cloud and aerosol layer products are used (Winker et al., 2009, 2010) for resolving aerosol extinction above apparent cloudtop heights in each respective product file (e.g., Yu et al., 2012; Alfaro-Contreras et al., 2014). The $532 \mathrm{~nm}$ abovecloud aerosol optical depth (ACAOD) is then solved by integrating the extinction coefficient over those corresponding 
bins (Liu et al., 2015; Kacenelenbogen et al., 2014). The CALIOP-based interannual variability analysis may be affected by CALIOP signal deterioration over time. Thus, collocated AERONET data sets are used, as first-order approximation, for evaluating instrument-related variation in the year-to-year variability in CALIOP AOD. Reported at eight spectral bands ranging from 0.34 to $1.64 \mu \mathrm{m}$ (Holben et al., 1998), AERONET AOD data sets are frequently used for validating satellite retrievals (e.g., Zhang et al., 2001; Yu et al., 2003; Kaufman et al., 2005a; Remer et al., 2005; Kahn et al., 2011; Shi et al., 2011; Sayer et al., 2012), as well as modelsimulated aerosol optical properties (e.g., Zhang et al., 2011, 2014).

The level 2.0 cloud-screened and quality-assured AERONET AOD data (Eck et al., 1999) from all available coastal and island AERONET sites are used for collocating CALIOP data. AERONET AOD data are interpolated, based on a method described in Zhang and Reid (2006), to the $0.532 \mu \mathrm{m}$ CALIOP wavelength and are spatiotemporally collocated with CALIOP AOD data. Year-to-year changes in AOD retrieved from the CALIOP instrument are investigated by calculating the global monthly mean AERONET and CALIOP AODs and comparing the two monthly aerosol loading averages. CALIOP observations found to be within $0.3^{\circ}$ latitude/longitude and $\pm 30 \mathrm{~min}$ of corresponding AERONET observations are considered collocated in space and time (see Omar et al., 2013, for a summary of the limitations regarding pairing CALIOP and AERONET observations). In addition, we have used only pairs that have collocated AERONET AOD $(0.532 \mu \mathrm{m})$ data less than 0.2 to exclude major aerosol episodes of continental origin. One additional quality assurance step is applied to exclude pairs with CALIOP AOD of larger than 0.6 for removing potentially noisy CALIOP data. In the case where several CALIOP observations are paired up with a single AERONET retrieval, a one-to-one relationship is established with the closest CALIOP observation.

OMI AI are used to isolate ACA events in those data. OMI AI and MODIS cloud data sets are spatiotemporally collocated, given their position in the NASA A-Train constellation (e.g., Stephens et al., 2002), by collocating the two products with respect to overpass times and then identifying all temporally collocated cloudy MODIS pixels located within the boundaries of the OMI footprint. Such methods are described further in Alfaro-Contreras et al. (2014). Cloud fractions from the collection 5.1 MODIS MYD06 product, which are used to determine the opaqueness of the MODIS scenes, are reported at a $5 \mathrm{~km}$ horizontal resolution, are then leveraged for sub-pixel cloud clearing of the OMI AI. The MODIS cloud fraction is computed from the percentage of cloudy $1 \mathrm{~km}$ cloud mask product (MOD35) pixels within a given $5 \mathrm{~km}$ scene (e.g., Ackerman et al., 1998). It should be noted that this MODIS cloud fraction is reported regardless of the success of cloud optical property retrievals (e.g., cloud optical depth and liquid water path). Then, OMI and MODIS data are each filtered and quality-assured (described in detail in Alfaro-Contreras et al., 2014) to calculate respective global ACA distributions. The OMI and MODIS data are spatially and temporally collocated, and the collocated OMI AIs are assigned to $100 \%$ cloudy MODIS scenes (as determined by MODIS, with a COD $>0$ ). This collocation process and methods are further described in Alfaro-Contreras et al. (2014). However, cloud inhomogeneity is not considered, and we leave the topic for another study.

If multi-layer clouds exist, MODIS can only resolve the highest cloud layer most of the time. Thus, we focus on the highest-level clouds in any given atmospheric column using CALIOP cloud layer products for a more accurate representation between the two techniques. The CALIOP data are filtered based on the study by Yu et al. (2012), where aerosol layers found with "medium" or "high" confidence are used. Note that, initially, cloudy scenes are defined as CALIOP COD $>0$ for the CALIOP-based method and no QA steps are applied to the CALIOP cloud layer products to ensure the detection of all possible ACA events. The effect of QA flags from the CALIOP cloud layer products on the detected CALIOP ACA frequency is further explored in Sect. 4.2 (as well as shown in Devasthale and Thomas, 2011). It is known that OMI has experienced row anomalies since 20082009 (http://www.knmi.nl/omi/research/product/). Thus, the impact of the row anomalies on the interannual variability in ACA occurrence derived from OMI AI is explored later in this paper.

\section{Above-cloud aerosol baselines and limitations}

There are always aerosol particles above clouds (a fact that quickly becomes neglected when discussing the basic physics of ACA relative to satellite observation). Therefore, there exist some baseline thresholds by which active backscatter and/or passive radiances become significant relative to a given physical process or retrieval (i.e., radiative forcing, heating rates, transmission estimates, cloud microphysical retrievals, etc.). Accordingly, each of the instruments subject to the ACA phenomenon in this study exhibits fundamental sensitivities to ACA detection, which impact our ability to characterize the problem fully. Therefore, the baseline thresholds for significant ACA events need to be identified for both OMI- and CALIOP-based ACA studies.

To conceptualize the problem, we look at the globally averaged cloud-top height for clouds located under aerosol plumes, which is found to be roughly $2.0 \mathrm{~km}$ and compares well with previous studies (Devasthale and Thomas, 2011). Thus, we consider the unique AERONET site at Mauna Loa, Hawaii $\left(19.539^{\circ} \mathrm{N}, 155.578^{\circ} \mathrm{W}\right.$; $3397 \mathrm{~m}$ above mean sea level). This free-tropospheric ground site rests at an altitude roughly within the global mean cloudtop heights. Indeed, this physical feature of the site (that is, most commonly being above a cloud deck below) is one 
of the key reasons for the importance of the site globally. The yearly mean level 2.0 AERONET AOD $(500 \mathrm{~nm})$ there ranges from 0.013 to $0.023(500 \mathrm{~nm})$ from 1996 to 2013 and provides a generalized estimate for potential baseline ACAOD value globally. Kacenelenbogen et al. (2014) report that the CALIOP lidar exhibits limitations in detecting ACA plumes with ACAOD less than 0.02. This lower value may, therefore, represent an effective noise floor, whereby the CALIOP algorithm response below it is compromised.

Based on Kacenelenbogen et al. (2014), combined with the AOD climatology from the Mauna Loa AERONET site analyses, we set the baseline CALIOP ACAOD value to 0.015 . Still, the CALIOP ACAOD baseline of 0.015 is arbitrary. We thus investigate CALIOP-based ACA frequency distributions by varying the baseline values to $0,0.01,0.015$, and 0.02 as shown in Fig. 1. Figure 1a-d show the cloudy-sky global ACA frequency distribution from CALIOP, defined in Table 1, for the December-May period, for baseline ACAODs of 0 (Fig. 1a), 0.01 (Fig. 1b), 0.015 (Fig. 1c), and 0.02 (Fig. 1d), using the CALIOP aerosol layer data sets. Note that, different from the cloudy-sky frequency, another way of measuring ACA frequency has been proposed by Devasthale and Thomas (2011) and is referred as the all-sky frequency from CALIOP in this study, also defined in Table 1. The difference between the two techniques is discussed in more detail during the section analyzing the year-to-year variation in ACA frequency occurrence.

Shown in Fig. 1, no clear difference is observed in the cloudy-sky ACA frequency by applying various CALIOP ACAOD baselines. A similar conclusion can also be made for the June-November period (Fig. 1e-h). Thus, for the purposes of this paper, the baseline CALIOP ACAOD value of $0.015(0.532 \mu \mathrm{m})$ is chosen, and the sensitivity of ACA interannual variability to the selection of the baseline CALIOP ACAOD is explored in a later section. Additionally, our selection of CALIOP ACAOD baseline has little effect on the background cloudy-sky ACA frequency, which is for the most part less than $5 \%$ (dark blue) globally. Thus, we arbitrarily select $5 \%$ as the threshold between background and significant cloudy-sky ACA frequencies. For the remainder of the paper, ACA frequencies less than $5 \%$ are not considered for global distributions of ACA frequencies (except for sensitivity and case studies).

To derive the corresponding noise floor value for abovecloud OMI AI, a pairwise comparison of collocated abovecloud OMI AI and CALIOP AOD has been performed using 1 year (2007) of collocated OMI-MODIS and CALIOP data, as described in Alfaro-Contreras et al. (2014), though without any limitations on the cloud-top height. Figure 2a depicts the relationship between binned above-cloud OMI AI and CALIOP AOD segregated into six different underlying MODIS-derived CODs (Yu et al., 2012; Torres et al., 2012). The bin-averaged CALIOP ACAOD of 0.015 , which reflects the baseline CALIOP ACAOD value chosen above, corresponds to OMI AI values of 0.7-1.2 for underlying MODIS
CODs ranging from 0 to 20. Note that, if CALIOP ACAODs are biased low, the corresponding OMI AI thresholds may bias high using methods as shown in Fig. 2a.

Still, as suggested from Fig. 2a, baseline values of OMI AI vary from 0.7 to 1.2 depending on the underlying cloud properties. To further explore the issue, detected ACA events are evaluated using different baseline OMI AI values, similar to the CALIOP ACAOD baseline analysis and shown in Fig. $2 \mathrm{~b}-\mathrm{i}$, though using only those bin averages with cloudysky ACA frequency greater than $5 \%$. Figure $2 \mathrm{~b}-\mathrm{e}$ depict the multi-year (2006-2013) cloudy-sky ACA frequency global average for the December-May period by applying AI baseline thresholds of 0.7 (Fig. 2b), 0.8 (Fig. 2c), 0.9 (Fig. 2d), and 1.0 (Fig. 2e). With the use of the baseline OMI AI value of 0.7 , most of the remote southern oceans $\left(30\right.$ to $60^{\circ} \mathrm{S}$; Toth et al., 2013) stand out for significant case numbers. By increasing the AI baseline value to 1.0, in contrast, detected ACA events are significantly reduced. A similar conclusion can also be drawn from the June-November period (Fig. 2fi). Given that hand-held shipborne sun photometer measurements collected by the Marine Aerosol Network (MAN; Smirnov et al., 2011) show an averaged AOD $(0.55 \mu \mathrm{m})$ of 0.07 or less from 30 to $60^{\circ} \mathrm{S}$ (Toth et al., 2013), significant ACA events are not likely over remote southern oceans. Thus, based on Figs. 1 and 2, CALIOP ACAOD of 0.015 and an above-cloud OMI AI of 1.0 are chosen as baselines. As we have now defined our baseline thresholds for ACA from both OMI and CALIOP, this enables us to create definitions of the various ACA frequencies used throughout this study, which are shown with further detail in Table 1.

Selection of baseline CALIOP ACAOD and OMI AI is clearly subjective and is done for qualitative analysis in subsequent sections. There are multiple caveats that must be considered before constraining these values more accurately and representatively. First, as mentioned earlier, the CALIOP instrument has issues in detecting distinct optically thin aerosol layers, especially during daytime. Additionally, it has been reported that CALIOP has a decreased sensitivity to stratospheric aerosols layers (Thomason et al., 2007; Winker et al., 2009). Third, besides aerosol loading, OMI $\mathrm{AI}$ is also sensitive to parameters such as aerosol vertical distribution, optical depth of underlying cloud, and aerosol single-scattering albedo (e.g., Yu et al., 2012). Thus, setting a seasonally and regionally based baseline for ACA requires a more in-depth analysis and should be considered in future studies. Still, this study presents the first ever attempt to solve ACA baselines, and the thresholds selected are the best noise floors we can derive with the given inputs. 
Table 1. Various definitions of frequency of above-cloud aerosols (ACA) used throughout the study.

\begin{tabular}{|c|c|c|}
\hline Name & Data set & Definition \\
\hline $\begin{array}{l}\text { Cloudy-sky ACA } \\
\text { frequency (passive) }\end{array}$ & OMI-MODIS & $\begin{array}{l}\text { (no. of MODIS observations with assigned AI }>\text { AI baseline and cloud } \\
\text { fraction equal to } 1 \text { )/(no. of MODIS observations with cloud fraction } \\
\text { equal to } 1 \text { and valid AI retrieval) per latitude and longitude grid over } \\
\text { given time period }\end{array}$ \\
\hline $\begin{array}{l}\text { All-sky ACA frequency } \\
\text { (passive) }\end{array}$ & OMI-MODIS & $\begin{array}{l}\text { (no. of MODIS observations with assigned AI >AI baseline and cloud } \\
\text { fraction equal to 1)/(no. of total MODIS observations per latitude and } \\
\text { longitude grid over given time period) }\end{array}$ \\
\hline $\begin{array}{l}\text { Cloud-sky ACA frequency } \\
\text { (active) }\end{array}$ & CALIOP & $\begin{array}{l}\text { (no. of CALIOP observations with AOD }>\text { AOD baseline located } \\
\text { above a cloud with COD }>0 \text { )/(no. of CALIOP observations with } \\
\text { COD }>0 \text { ) per latitude and longitude grid box over given time period }\end{array}$ \\
\hline $\begin{array}{l}\text { All-sky ACA frequency } \\
\text { (active) }\end{array}$ & CALIOP & $\begin{array}{l}\text { (no. of CALIOP observations with AOD }>\text { AOD baseline located } \\
\text { above a cloud with COD }>0 \text { )/(total no. of CALIOP observations) per } \\
\text { latitude and longitude grid box over given time period }\end{array}$ \\
\hline Cloudy-sky frequency & MODIS & $\begin{array}{l}\text { (no. of observations with cloud fraction of unity }(\mathrm{CF}=1) / \text { total no. of } \\
\text { MODIS observations) }\end{array}$ \\
\hline
\end{tabular}
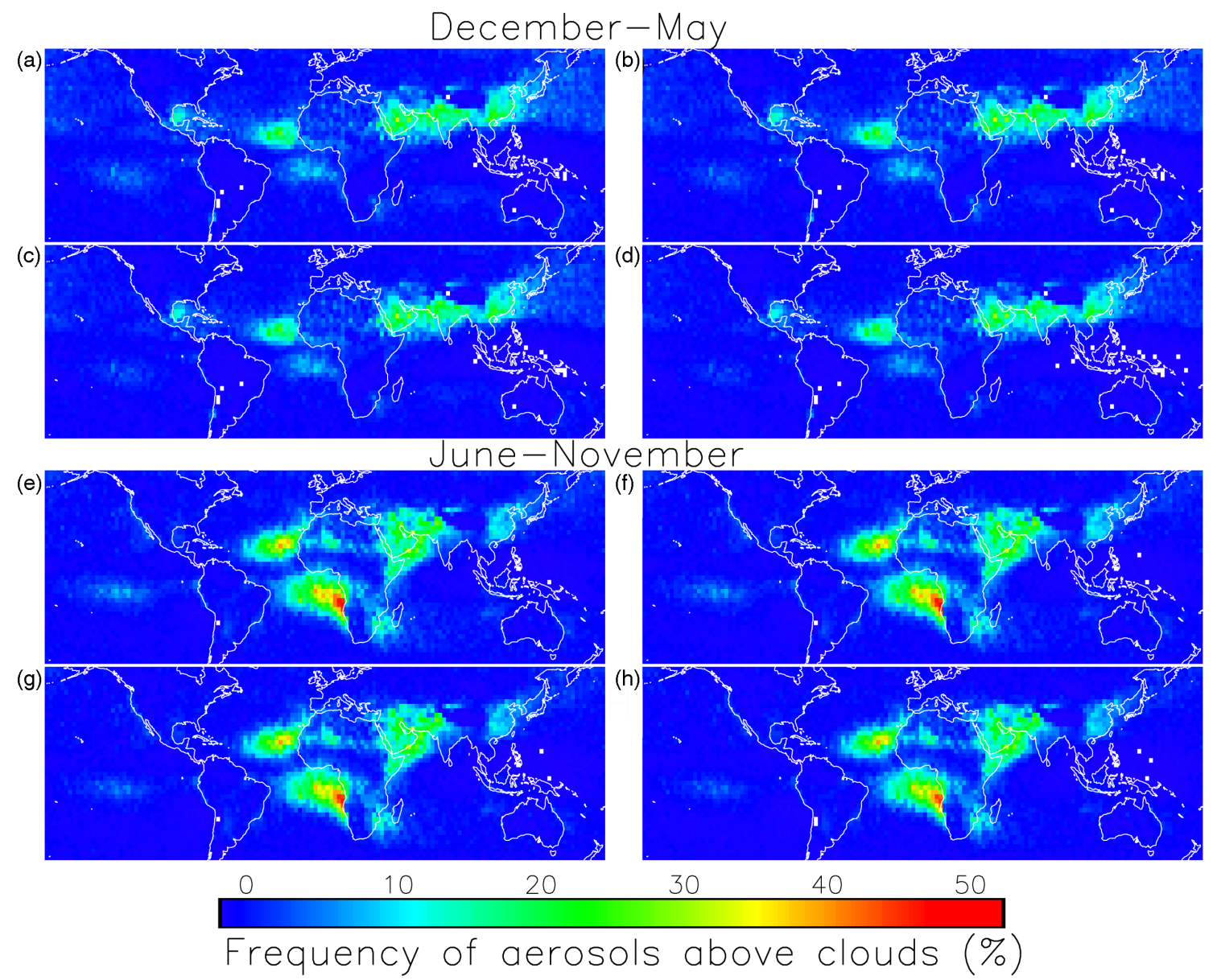

Figure 1. (a-h) Multi-year (2006-2013) CALIOP-derived daytime global cloudy-sky ACA frequency applying different CALIOP AODs as the threshold between background and significant aerosol loading. The CALIOP AODs are binned into $2.5^{\circ} \times 2.5^{\circ}$ bins derived using the CALIOP cloud and layer data sets. CALIOP AOD baseline thresholds of 0, 0.010, 0.015, and 0.020 are applied to (a, b, c, d), respectively, for the December-May period. Panels (e-h) show similar results to (a-d) but for the June-November period. 

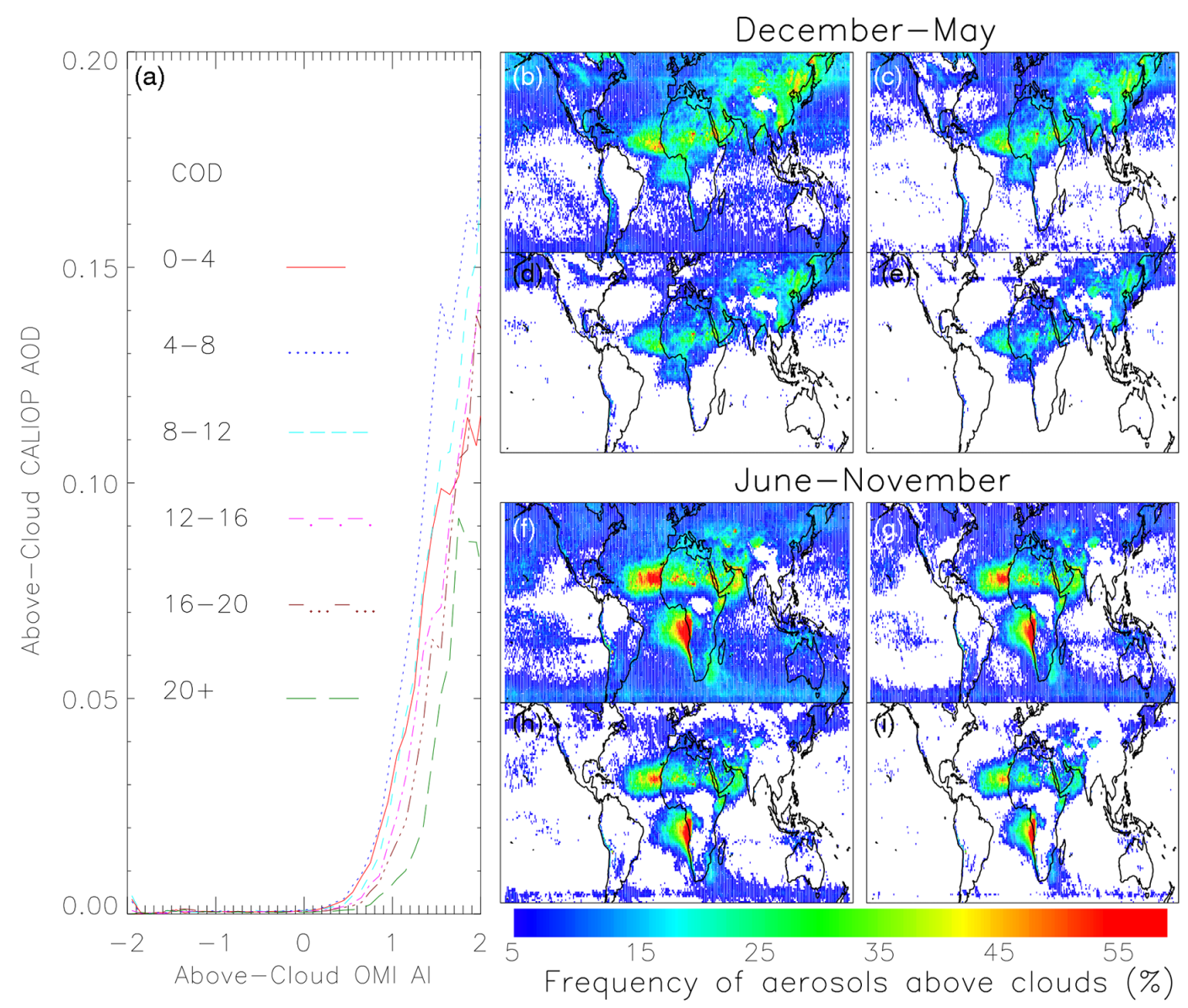

Figure 2. (a) Pairwise comparison between collocated OMI and CALIOP observations of above-cloud AI and AOD, respectively, as a function of the underlying MODIS cloud optical depth (COD). CALIOP AODs are averaged into OMI AI bins of 0.1. (b-i) Multi-year (2006-2013) daytime global cloudy-sky ACA frequency applying several different OMI AIs as the threshold between background and significant aerosol loading. The OMI AIs are binned into $1^{\circ} \times 1^{\circ}$ bins derived from the MODIS-OMI collocated data set. OMI AI baseline thresholds of 0.7, 0.8, 0.9, and 1.0 are applied to (b, c, d, e), respectively, for the December-May period. Panels (f-i) depict the same information as (b-e) but for the June-November period. ACA frequencies less than $5 \%$ are shown in white.

\section{Comparison of ACA global climatology using two separate techniques}

\subsection{ACA global climatology from all available MODIS, OMI, and CALIOP data}

Figure $3 \mathrm{a}$ depicts the multi-year gridded mean near-global distribution $\left(180^{\circ} \mathrm{W}\right.$ to $180^{\circ} \mathrm{E}, 45^{\circ} \mathrm{S}$ to $\left.60^{\circ} \mathrm{N}\right)$ of the OMIderived daytime cloudy-sky ACA frequency (defined in Table 1) for December to May. Figure $3 b$ and c show corresponding cloudy-sky daytime and nighttime frequencies, respectively, using CALIOP data (defined in Table 1). Figure $3 \mathrm{~d}-\mathrm{f}$ show the corresponding information to Fig. $3 \mathrm{a}-\mathrm{c}$ for June to November.

Comparison of daytime cloudy-sky ACA frequency distribution is consistent between the two sensors and seasonal periods investigated, and depicted in Fig. 3g-j. Some differences are distinct during December-May, as cloudy-sky
ACA frequencies as high as $10 \%$ are visible over the Gulf of Mexico from CALIOP, for instance, whereas they are non-existent from OMI-MODIS (Fig. 3a). Cloudy-sky ACA frequencies of $20-30 \%$ are found with OMI-MODIS over high-latitude northern Asia, in contrast with CALIOP, which shows no such activity (Fig. 3i). During June-November, both methods resolve ACA events over the west coast of Africa, as well as over the Middle East, of similar magnitude $(10-60 \%)$. However, distinct differences can be found between the two data sets. Higher cloudy-sky ACA frequency values of $10-30 \%$ are found over northern Africa using OMI-MODIS, in contrast with much lower values of 10-20\% found using CALIOP, for example. An OMI-based ACA study should correspond to a higher noise floor compared with that of an active sensor, based on OMI's much coarser spatial and vertical resolutions, an inability to resolve non-UV absorbing aerosols, and the fundamental decoupling of column-integrated radiances themselves. Still, if the OMI 
AI baseline is biased, it may introduce an additional difference between OMI-MODIS- and CALIOP-based ACA frequencies.

Cloudy-sky ACA frequencies as high as $10-30 \%$ are found over northern Africa for both periods from OMIMODIS, while CALIOP returns much lower percentages (10-20\%) over the same region. This region is dominated by dust particle transport (Kaufman et al., 2005b), which is detected by both OMI and CALIOP. Therefore, we suspect that their relative differences as derived in Fig. $3 i$ and $j$ are likely linked to the misidentification of thick dust plumes as clouds by the MODIS cloud-masking scheme over bright desert surfaces (e.g., Levy et al., 2013). Such a misclassification is also illustrated in a case study (8 July 2007, over the Saharan region) as shown in Fig. 4. Over a section of CALIOPdetected cloud-free aerosol-polluted regions $\left(15-30^{\circ} \mathrm{N}, 2-\right.$ $6^{\circ} \mathrm{W}$ ), where OMI AI values are above 2, cloud fraction of a unit (fully cloud cover) is reported by the MODIS MYD06 product, indicating a potential misclassification of aerosol plumes as clouds in the MODIS MYD06 product. Further differences observed between the two data sets may also be due to different algorithmic sensitivities exhibited relative to the optical depth of both the underlying cloud and overlying aerosol plume, the OMI AI and CALIOP AOD noise floors used to define the ACA events, the particular QA settings applied to any of our data sets, differences in cloud-detection techniques between CALIOP and MODIS, or the inability of OMI to detect all aerosol types. We further explore this issue in Sect. 4.2.

Compared with daytime, increases in both the spatial extent and cloudy-sky CALIOP ACA frequencies are observable at night, as seen from Fig. 3b, c, e, and f, over most regions. Over the most common ACA regions, nighttime cloudy-sky ACA frequencies can be 10-30\% higher than during day, which may partially due to the stronger sensitivity of CALIOP at night, allowing for detection of optically thin aerosol plumes. In particular, ACA events are observed with extended frequency over the west coast of North America year-round and over the west coast of South America for the June-November period. Cloudy-sky ACA frequencies at night, over both of these regions, are composed of optically thin aerosol loading cases above our defined noise floor. Nighttime ACA events are also observed over the east coast of Asia year-round. One reason for differences in spatial coverage between daytime and nighttime ACA events is plausibly linked to a lower planetary boundary layer that affects the formation of low clouds (e.g., Schrage and Fink, 2012). Still, the discrepancy between nighttime and daytime ACA events can be partially attributed to the potential detection of relatively diffuse ACA plumes that are more detectable during nighttime compared with day as a result of the higher signal to noise ratio for CALIOP nighttime data (e.g., Kacenelenbogen et al., 2014).

Shown in Fig. 5 are averaged above-cloud OMI AI and CALIOP AOD values for corresponding ACA events from
Fig. 3. Figure 5a depicts the mean near-global distribution of OMI AI over MODIS-resolved cloudy skies, defined as OMI-MODIS collocated cloudy pixels (cloud fraction of unity) and OMI AI averaged for each $1^{\circ} \times 1^{\circ}$ grid box, during December to May. Only bins with averaged AI greater than 1.0 are plotted in accordance with our defined noise floor. Also, for December-May, Fig. 5b depicts multiyear mean gridded daytime CALIOP ACAOD averaged for each $2.5^{\circ} \times 2.5^{\circ}$ grid box for CALIOP-defined cloudy pixels $(\mathrm{COD}>0)$, using only bin-averaged ACAOD greater than 0.015 . Figure $5 \mathrm{c}$ features the same information as Fig. $5 \mathrm{~b}$ but for nighttime CALIOP retrievals.

During the December-May period, elevated OMI AI values are observed over the Sahara region of northern Africa, as well as in Southeast Asia off the coast of northern Vietnam. In comparison with OMI AI, CALIOP AOD shows a much broader distribution of AODs greater than the baseline (ACAOD > 0.015) for the entire globe. Bin-averaged AIs greater than the baseline (AI>1.0) are sparse during the winter and spring months. Additionally, optically thin aerosol plumes are observed over the northern Pacific Ocean during the CALIOP nighttime analysis (Fig. 5c) when compared to the daytime (Fig. 5b).

Figure $5 \mathrm{~d}-\mathrm{f}$ depict the same information as Fig. 5a-c but for the June-November period. This period exhibits a relatively large overall distribution of ACA events. In addition to the Saharan dust outbreaks, elevated AI and AOD values over the southern Africa smoke region are also found from both OMI and CALIOP data sets, respectively. This period exhibits large aerosol loading and ACA frequency over southern Africa and the southeast Atlantic Ocean. High values of ACAOD are also found over the Indian Ocean and Arabian Sea, likely due to the transport of dust aerosols from the east Saharan and Arabian Gulf regions (Satheesh et al., 2006). From comparison of Figs. 3 and 5 over regions such as the west coast of South and North America, it is clear that cloudy-sky ACA frequencies are mostly attributable to relatively low aerosol loading events. Figure 5 shows a drastically reduced distribution of averaged OMI AIs above the AI baseline (1.0) in comparison to averaged CALIOP ACAODs above the AOD baseline (0.015).

Again, differences are visible here between day- and nighttime CALIOP AOD distributions. Off the southwest coast of Africa, the development of marine stratus-type clouds, as suggested from Fig. 6, may lead to higher ACAOD values at night. Over India and the Middle East, we suspect that higher daytime ACAOD values may exist. Still, a lower CALIOP signal-to-noise ratio during daytime may be a limiting factor that contributes significantly to the difference.

It is likely that most ACA events occur over low-level liquid-phase cloud decks. Therefore, spatial distributions of CALIOP-derived low-level clouds are investigated. Figure 6a (6b) depicts the daytime (nighttime) multi-year mean distribution of low-level clouds (defined as the ratio of CALIOP scenes with a COD $>0$ and cloud-top height $<3 \mathrm{~km}$ over to- 

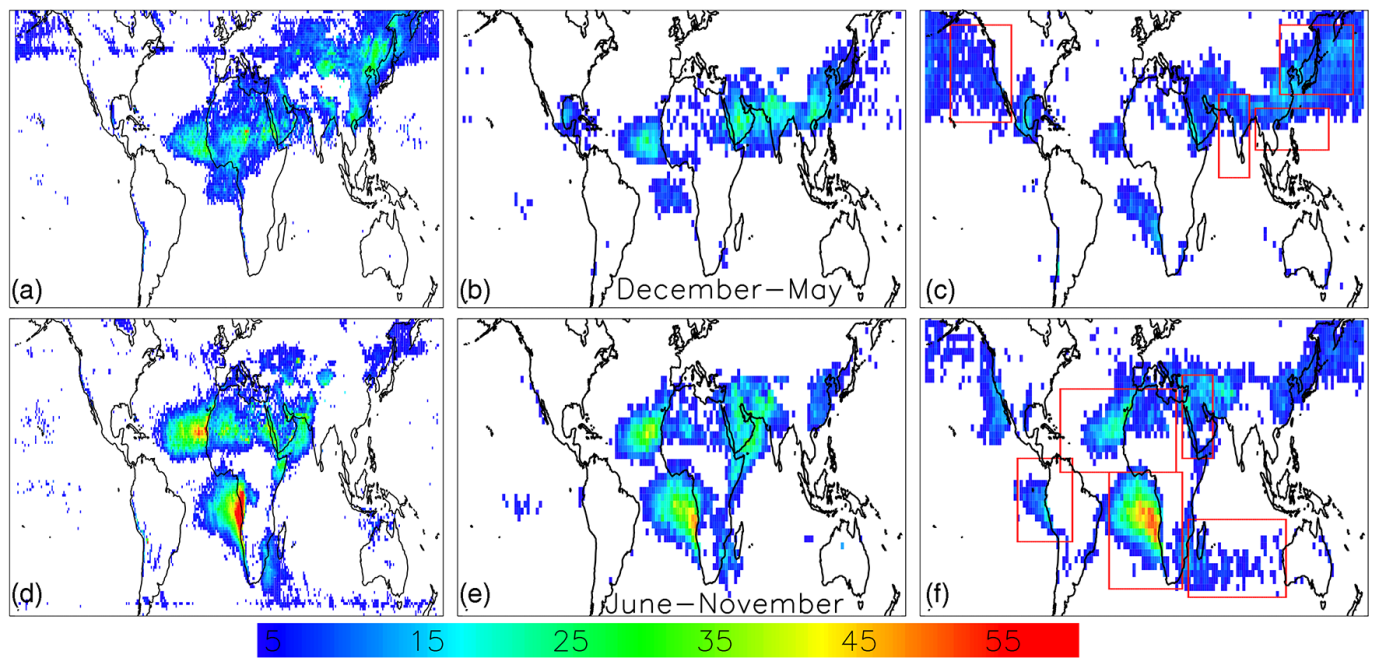

Frequency of aerosols above clouds (\%)
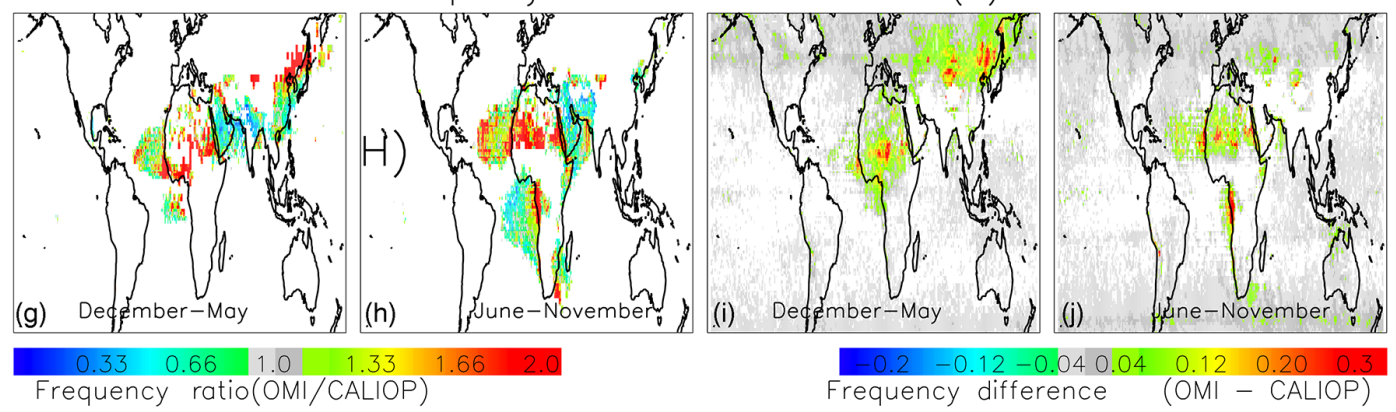

Figure 3. (a) Seven-year (December 2006 to May 2013) daytime cloudy-sky frequency of occurrence of aerosol above-cloud events during December through May defined from OMI (ratio of completely cloudy MODIS pixels with AI greater than 1.0 to the number of completely cloudy MODIS pixels with valid AI retrievals). (b) Daytime cloudy-sky frequency of occurrence of ACA events over cloudy skies from CALIOP (ratio of CALIOP pixels with CALIOP AOD above cloud $>0.015$ to the number of CALIOP pixels with column-integrated COD $>0$ ) for the same temporal domain as (a). (c) Nighttime cloudy-sky frequency of occurrence defined similar to the daytime frequency from (b). Panels (d-f) show the same information as (a-c) but instead during June 2006 to November 2013. Panels (g, h) depict the ACA frequency ratio, defined as the OMI-MODIS daytime cloudy-sky frequency divided by the CALIOP-derived daytime cloudy-sky frequency, for the December to May and June to November periods, respectively. Panels (i, j) depict the difference in cloudy-sky frequency used to construct the frequency ratio plots $(\mathbf{g}, \mathbf{h})$ for the same temporal ranges. The red boxes show the areas selected for regional studies. Only OMI and CALIOP bins with frequency of $5 \%$ or higher are shown in this analysis.

tal number of CALIOP scenes) during December-May for years 2006 to 2013. CALIOP cloud layer data are gridded into $2.5^{\circ} \times 2.5^{\circ}$ bins. Figure $6 \mathrm{c}$ and d depict the same information as Fig. $6 \mathrm{a}$ and $\mathrm{b}$ but from June to November for years 2006 to 2013. Figure 6e and $\mathrm{f}$ depict the ratio between daytime and nighttime low-level cloud frequencies per bin for the December-May period and June-November periods, respectively. The ratio is as high as 2.0 over the northern and southern Africa regions during June-November, as well as over the western US annually. Such a high ratio between day- and nighttime data leads to a nighttime frequency of 10 $20 \%$ low-level cloud coverage increase over most regions compared with daytime observations, plausibly due to diurnal boundary layer effects.

A significant percentage of CALIOP-derived low-level clouds are plausibly stratocumulus clouds, which are fre- quently observed over the west coasts of major continents (e.g., Wood et al., 2012). Qualitative comparison of Figs. 5 and 6 indicates reasonable consistency between high frequencies of CALIOP-defined low-level cloud formation and ACA loading. With the exception of the Saharan region, again due to the possible misclassification of thick aerosol plumes as clouds by MODIS discussed earlier, most ACA loading cases are found where the CALIOP-defined lowlevel cloud formation 6-month frequency exceeds $20 \%$. This indirectly confirms that most ACA outbreaks occur over CALIOP-defined low-level clouds.

It is also useful to evaluate ACA frequency relative to mean clear-sky AOD. Figure 7a-d depict the multi-year mean clear-sky CALIOP AOD for the same temporal and spatial domains as Fig. 5b, c, e, and f, respectively. As opposed to the cloud-sky ACA aerosol loading (Fig. 5), AOD 

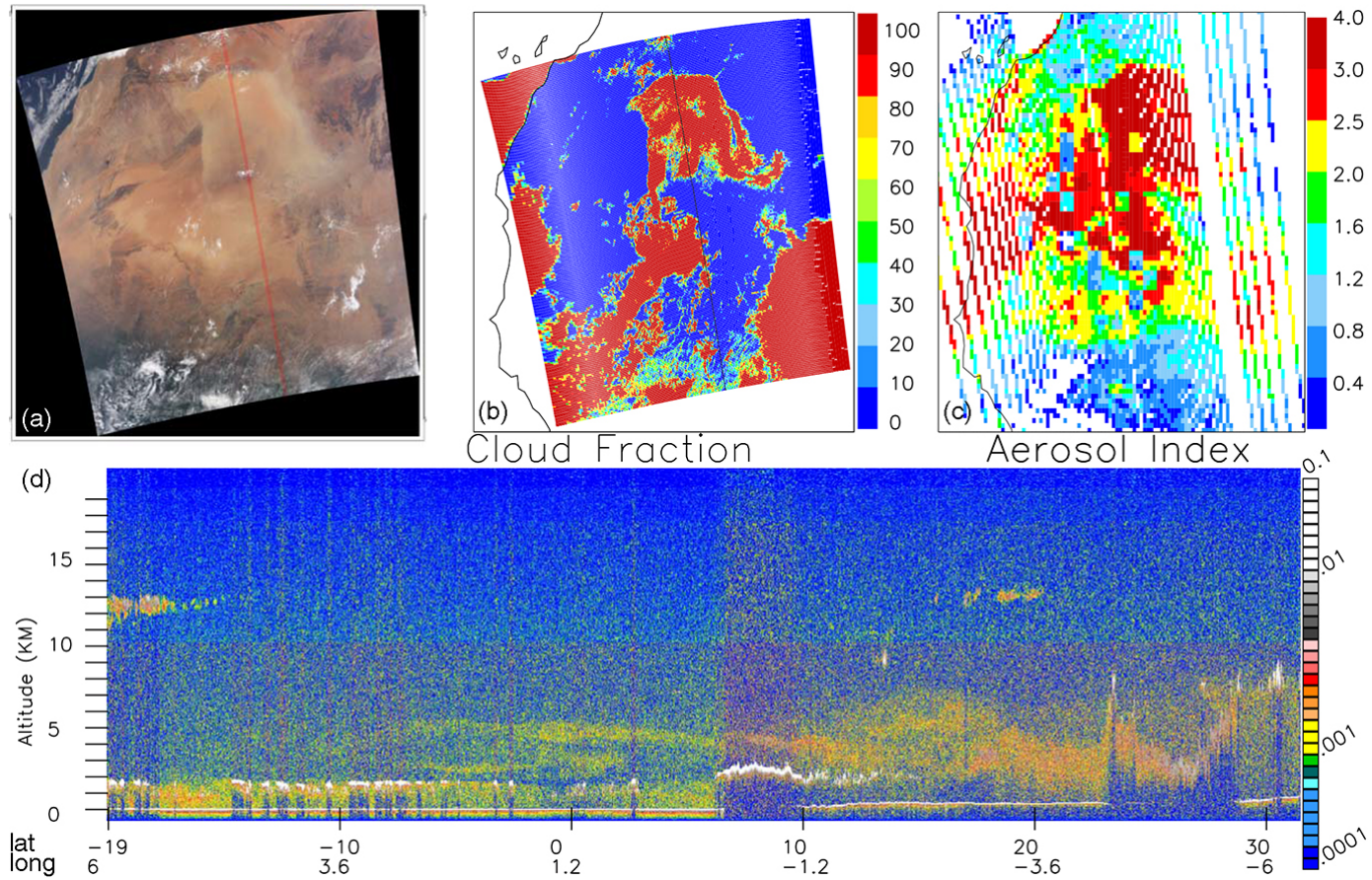

Figure 4. (a) Aqua MODIS true color image on 8 July 2007 over the Sahara in northern Africa. (b) The same domain as Figure 4a but for Cloud Fraction from the MODIS MYD06 data. (c) Similar to Fig. 3a but for OMI aerosol index (AI). Panel (c) is created by averaging all OMI observations into $0.25^{\circ} \times 0.25^{\circ}$ grids over the region shown. (d) The vertical profile for CALIOP backscatter, where the instrument overpass is superimposed on (a). Also, the CALIOP track shown in (a) is constructed by highlighting those MODIS observations that are collocated with CALIOP observations.

loading over clear skies shows more activity inland, as the formation of low-level clouds is more common over coastal regions (IPCC, 2007). An intercomparison among Figs. 5, 6 , and 7 suggests that ACA events do not necessarily follow clear-sky AOD patterns but rather those above-cloud aerosolpolluted regions with a high frequency of low-cloud presence.

\subsection{ACA global climatology from the collocated MODIS, OMI, and CALIOP data set}

As illustrated in Fig. 3 for the December-May daytime period, ACA events over northern Africa as derived from the OMI-MODIS-based method are not found from the CALIOP-based method. Also, ACA events over India, as reported from the CALIOP-based method, are not visible from the OMI-MODIS-based method. Similarly, for the JuneNovember period, ACA events over northern Africa reported from the CALIOP-based method are not as frequent as those seen from the OMI-MODIS-based method. Yet the ACA events detected from the CALIOP-based method over southern China are not visible from the OMI-MODIS-based method.

To identify differences between the OMI-MODIS- and CALIOP-based cloudy-sky ACA global climatology, a collocated data set has been constructed that includes spa- tially and temporally collocated MODIS, OMI, and CALIOP data for the period of June 2006 to November 2008. Note that no collocated data are available after November 2008 due to the row anomaly of OMI. All three sensors are on board the A-Train constellation, making temporal collocation less of an issue, and we require the observational times of the three data sets to be within \pm 30 min to be considered. To spatially collocate the three data sets, only MODIS (OMI) observations within $0.04^{\circ}\left(0.2^{\circ}\right)$ of the center of a CALIOP data point (from the $5 \mathrm{~km}$ CALIOP aerosol and cloud layer products) are used. Using the collocated OMIMODIS-CALIOP data set, differences in cloudy-sky OMIMODIS- and CALIOP-based ACA frequencies are studied as functions of CALIOP cloud and aerosol QA flags (Devasthale and Thomas, 2011), the differences between MODISand CALIOP-reported cloud coverages, and aerosol properties (UV-absorbing vs. non UV-absorbing aerosols).

Similar to Fig. 3a and b, Fig. 8a and $d$ show the cloudy-sky ACA frequency as detected by the CALIOPand OMI-MODIS-based methods, respectively, but with use of the OMI-MODIS-CALIOP collocated data set for the December-May period. Figure $8 \mathrm{~b}(8 \mathrm{e})$ and $8 \mathrm{c}(8 \mathrm{f})$ show the all-sky ACA frequency and cloudy-sky frequency for the CALIOP- (OMI-MODIS-) based methods. As mentioned in Table 1, all-sky ACA frequency is defined as the number of ACA events divided by all data points. Thus, Fig. $8 \mathrm{~b}$ (e) and 


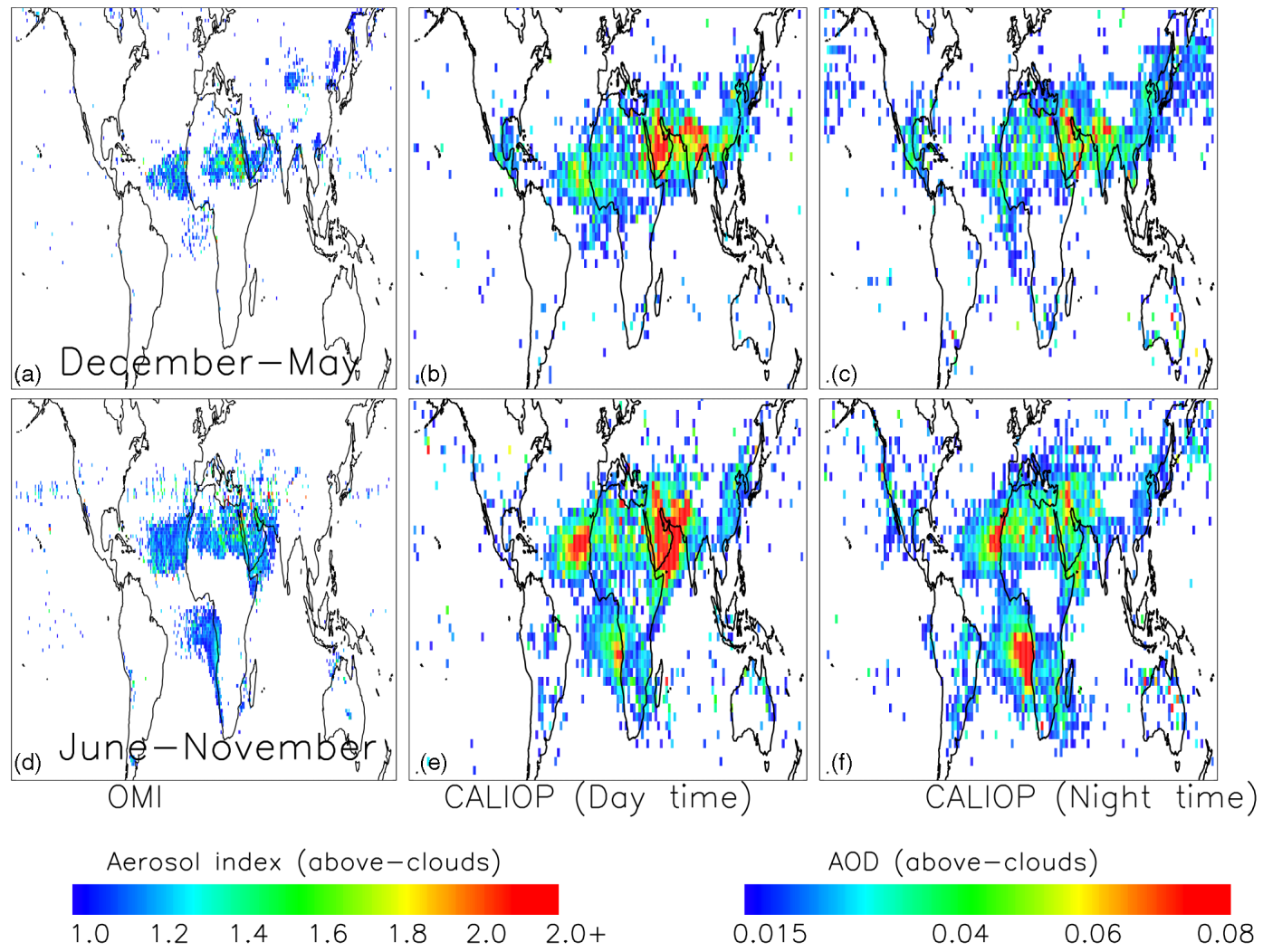

Figure 5. (a) Multi-year (2006-2013) daytime AI averaged into $1.0^{\circ} \times 1.0^{\circ}$ bins constructed from collocated MODIS and OMI AI over strictly MODIS cloudy scenes during December through May. The averaged OMI AI is neglected below 1.0 in accordance with the AI ground floor determined in Fig. 2. (b) Multi-year (2006-2013) daytime ACAOD averaged into $2.5^{\circ} \times 2.5^{\circ}$ bins derived from CALIOP cloud and aerosol layer products. Averaged CALIOP ACAOD values below 0.015 are considered below the noise floor for the study and thus are not shown. Panel (c) shows the CALIOP ACAOD similar to (b) except for nighttime observations. Panels (d-f) show the same information as (a-c) but during the summer and fall months (June-November).

c (f) can also be considered as ACA event data counts and cloudy-sky data counts for the CALIOP- (OMI-MODIS-) based method. Readers should be aware that the spatial distribution of MODIS cloud fraction, as shown in Fig. $8 \mathrm{f}$ and 1 , differs from the spatial distribution of cloud fraction obtained from the standard MODIS cloud products (e.g., King et al., 2013) for a few reasons. First, Fig. 8f and 1 are constructed using the MODIS cloud fraction values from a collocated OMI, CALIOP, and MODIS data set, and thus only nearnadir MODIS cloud mask data are used. Also, cloud fraction values (at a $5 \mathrm{~km}$ resolution) from the MODIS MYD06 product are used. To be consistent with the OMI-MODIS analysis, only the $5 \mathrm{~km}$ granules that are $100 \%$ cloudy (or twenty-five $1 \mathrm{~km}$ MODIS pixels within a $5 \mathrm{~km}$ granule are all cloudy) are counted as cloudy granules. Thus, broken and/or non-contiguous clouds may be excluded in the cloud fraction calculation.

The first thing to notice from these data is that cloudy-sky frequency from the CALIOP-based method is higher than that of the OMI-MODIS-based method. The differences in cloudy-sky frequencies are not unexpected, as the CALIOP- based method can detect optically thin clouds (such as thin cirrus clouds) for which ability the OMI-MODIS-based method is limited (e.g., Toth et al., 2013). Also, the all-sky ACA frequencies from CALIOP- and OMI-MODIS-based methods show similar magnitudes for both the DecemberMay and June-November periods. Thus, the higher cloudysky ACA events over northern Africa, as reported from the OMI-MODIS-based methods, are likely due to the differences in cloud detection capability among the different sensors.

For the December-May period, higher all-sky ACA frequency is reported from the CALIOP-based method over India. A similar situation is also found for the June-November period over Southeast Asia. While one would suspect that the greater number of ACA events over India and Southeast Asia regions could be due to the fact that the OMI-MODIS-based method is only sensitive to non-UV-absorbing aerosols, we also evaluated the issue with respect to CALIOP QA flags. Figure 9 shows global plots of cloudy-sky frequency and all-sky ACA frequencies from the original QA metrics used to generate Fig. 3, as well as global plots altering CALIOP 

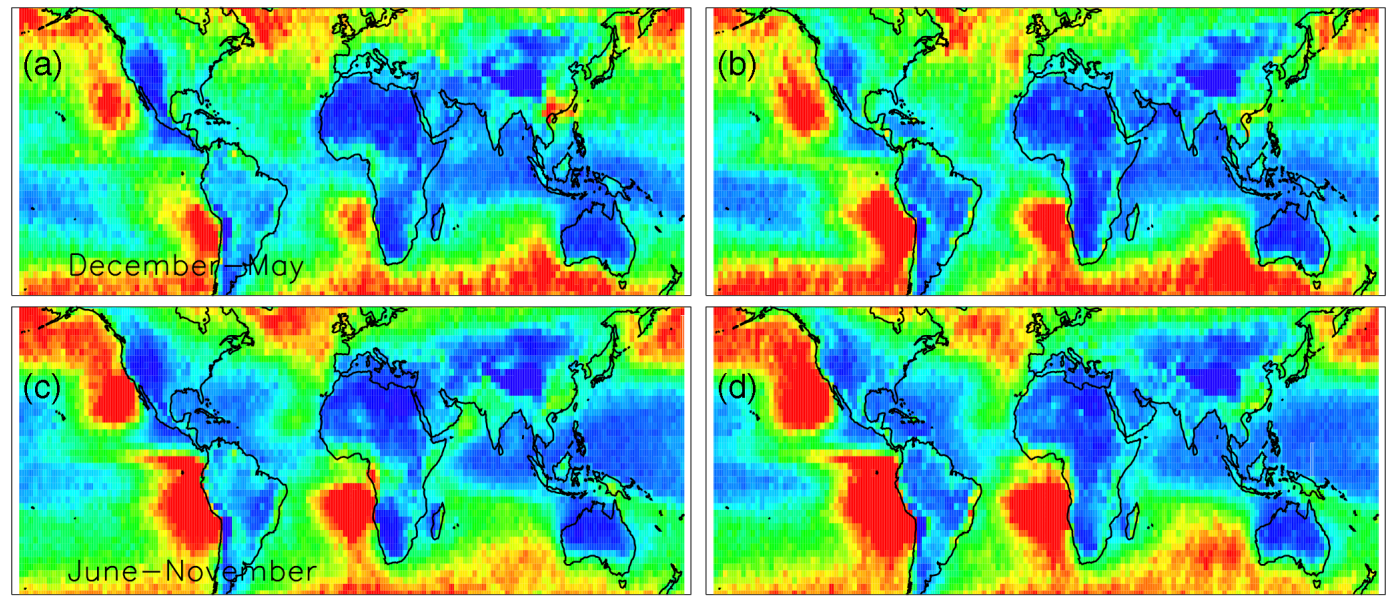

Frequency of Low-level clouds (\%)
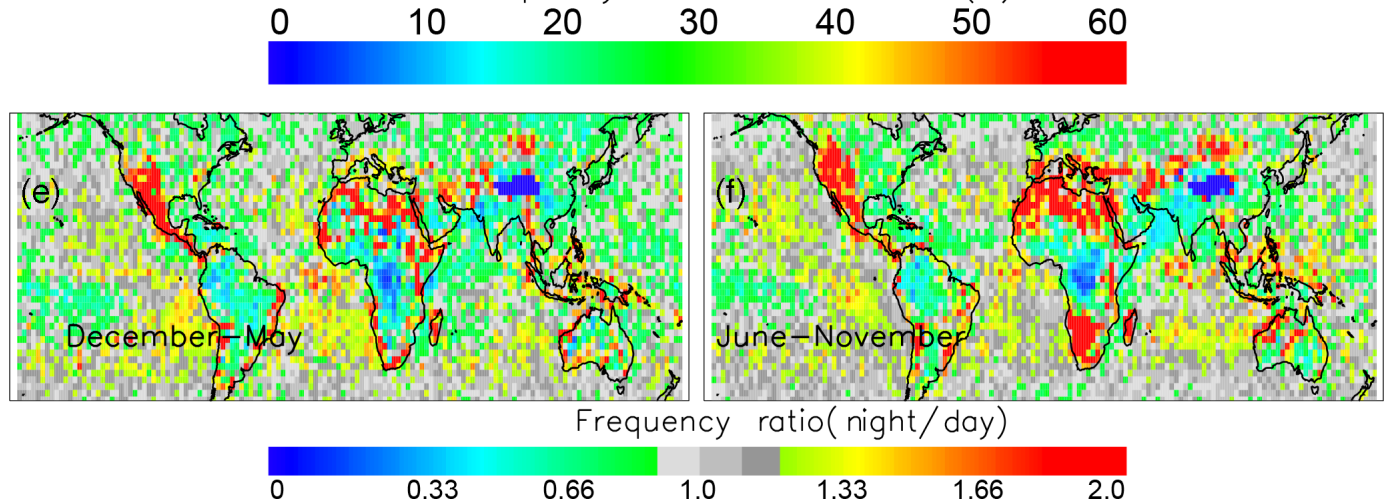

Figure 6. Multi-year (June 2006 to November 2013) frequency of occurrence of low-level clouds defined by CALIOP as the ratio of pixels with COD greater than 0 with cloud-top height $<3 \mathrm{~km}$ to the total number of CALIOP scenes within the current $2.5^{\circ} \times 2.5^{\circ}$ bin for (a) December to May during daytime observations, (b) December to May of nighttime observations, (c) daytime frequency of occurrence of low-level cloud decks defined similar to (a) during the June-November time frame, and (d) nighttime frequency of occurrence of low-level cloud decks for the same time frame as (c). Panels (e, f) depict the night- to daytime frequency ratio for the December to May and June to November periods, respectively.

aerosol and cloud QA flags to "lenient", "intermediate", and "strict". Here, the CAD scores and feature classification flags are used to define the quality of each retrieval. In order for a feature to be considered lenient, intermediate, or stringent quality, its CAD score absolute value must be greater than 0,20 , or 70 , respectively. In addition, the feature flag must also return at least "low", "medium", and "confident" result for the "lenient", "intermediate", and "stringent" QA levels, respectively as defined in Liu et al. (2009).

Figure 9a-c show the distributions of cloudy-sky frequency with the use of lenient, intermediate and strict CALIOP cloud QAs, respectively. These data reflect how cloud QA exhibits only a minor effect on the spatial distribution of cloudy-sky frequencies. Figure $9 d-f$ show the spatial distribution of all-sky ACA frequency with the "lenient" aerosol QA setting but with the cloud QA levels of "lenient", "intermediate", and 'strict', respectively. What can be clearly seen from Fig. 9d and e, with the changing of cloud QA setting from "lenient" to "intermediate", is that the CALIOP- based all-sky ACA frequencies are much reduced over northern Africa, the Middle East, India, and southern China. This indicates that a portion of the observed differences between the OMI-MODIS- and CALIOP-based methods may be due to cloud QA. Similarly, when we hold the cloud QA setting constant at "lenient" while varying the aerosol QA setting from "lenient" to "intermediate" and "strict" (Fig. 9g-i), no significant changes in all-sky ACA frequencies are found. We repeat the process for the June-November period, as shown in Fig. 9j-r, and similar conclusions are found.

The CALIPSO level 2 cloud and aerosol layer products include cloud retrievals conducted using horizontal averages at the three extended settings (e.g., 5, 20, or $80 \mathrm{~km}$ averages). While $5 \mathrm{~km}$ averaging detects the most "reliable" cloud and aerosol signals, the $80 \mathrm{~km}$ averaging locates features with "weaker" signals (Vaughan et al., 2009). Since the CALIPSO level 2 cloud and aerosol layer products are used in this study, the results presented here shall include horizontal averages from the three settings as mentioned. In addition, us- 


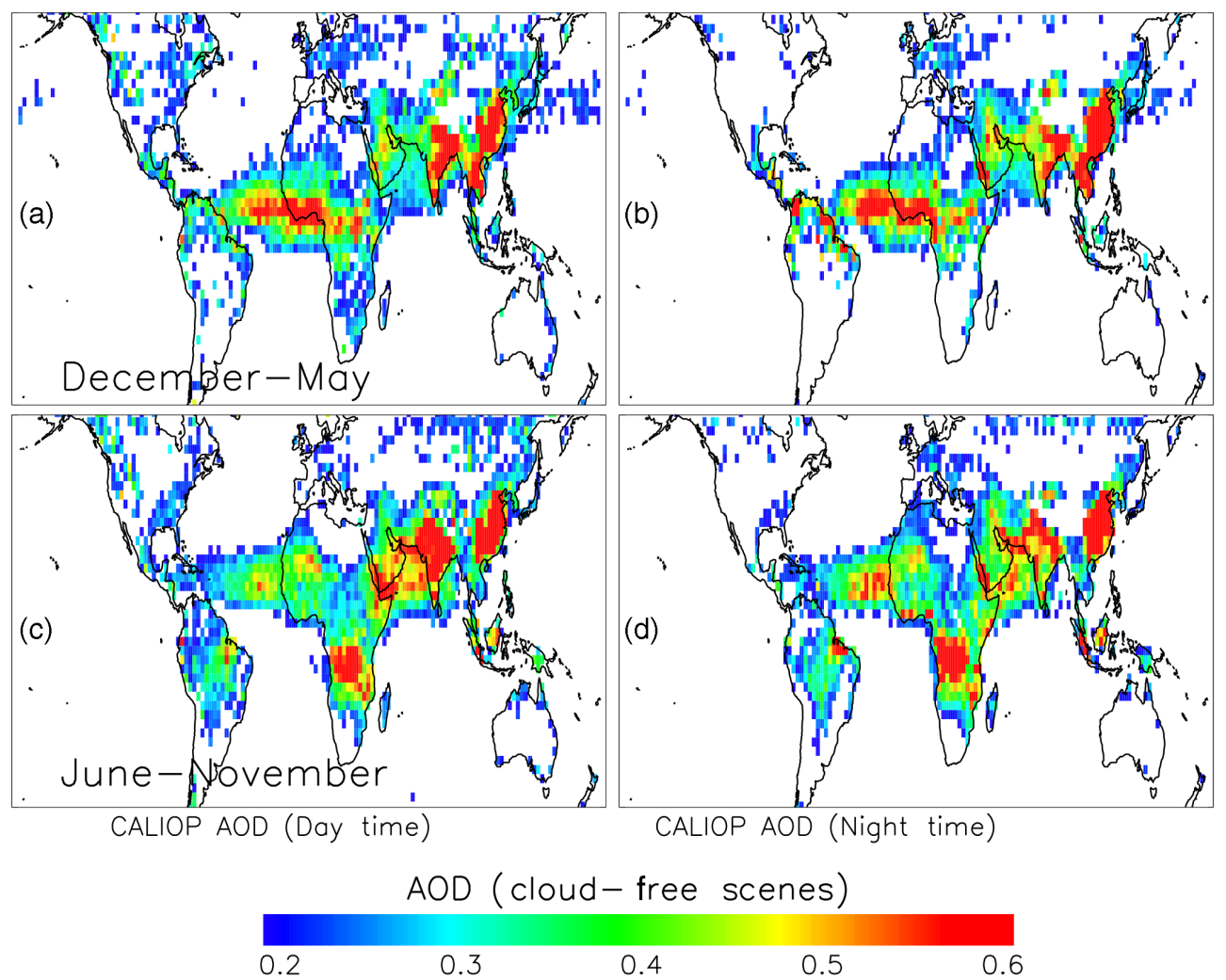

Figure 7. Multi-year (2006-2013) $2.5^{\circ} \times 2.5^{\circ}$ averaged CALIOP daytime AOD for (a) December through May over completely cloudfree scenes derived from CALIOP cloud and aerosol layer daytime analysis, (b) nighttime analysis during the December to May period, (c) daytime analysis for the June to November period, and (d) nighttime analysis for the June to November period. Only scenes which contained an averaged $\mathrm{AOD}>0.2$ with a column $\mathrm{COD}=0$ were used in the analysis.

ing CALIOP's ability to distinguish different aerosol types, we find that absorbing aerosols (dust, smoke, and polluted dust) constitute about $80 \%$ of ACA particles over southeast Asia during June-November, and more than $90 \%$ over India during the December-May period. Thus, OMI's inability to detect all aerosol types may play a minor role in the observed ACA frequency differences over these regions. However, the differences in cloud detection capability, the QA settings, and their arbitrary thresholds used are instead likelier to be the primary causes of the discrepancies between OMI-MODISand CALIOP-based methods. Still, aerosol type discrimination from CALIOP measurements has its own limitations, and we leave this topic for a future paper to explore.

\section{Interannual variability of global ACA frequency}

An analysis of the year-to-year variation in global cloudsky ACA frequency is carried out for five different scenarios. The different scenarios are OMI daytime cloudy-sky frequency, CALIOP daytime cloudy-sky and all-sky frequencies, and CALIOP nighttime cloudy-sky and all-sky frequencies. As suggested in Sect. 4.2, only CALIOP data with both cloud and aerosol QA settings as either "medium" or "high- est" confidence levels are used hereafter. Figure 10 shows CALIOP daytime cloudy-sky frequency (red) and all-sky frequency (blue), CALIOP nighttime cloudy-sky frequency (orange) and all-sky frequency (purple), and OMI daytime cloudy-sky frequency (green). Each data point represents the global monthly mean ACA frequency of CALIOP and OMI calculated from $2.5^{\circ}$ and $1^{\circ}$ gridded ACA frequencies, respectively.

An increase in the OMI cloudy-sky ACA frequency over the study period is apparent in this global data set, most noticeably since 2009 . However, this interannual variability is not matched in the CALIOP data. The seasonal variation in ACA frequency is observed from year to year for both OMI and CALIOP (dashed lines). However, from the year-to-year variation lines (showing a percentage change per year), only the OMI daytime cloudy-sky frequency shows a significant increase over this time period (solid lines). The increasing interannual variability in OMI-derived daytime global cloudy-sky ACA frequency, which is not apparent in any of the CALIOP-derived global cloudy-sky ACA frequencies, is troublesome and may be attributed to any of the different sensitivities of the two techniques, including cloud and aerosol optical properties, aerosol-cloud separation distance, and/or 


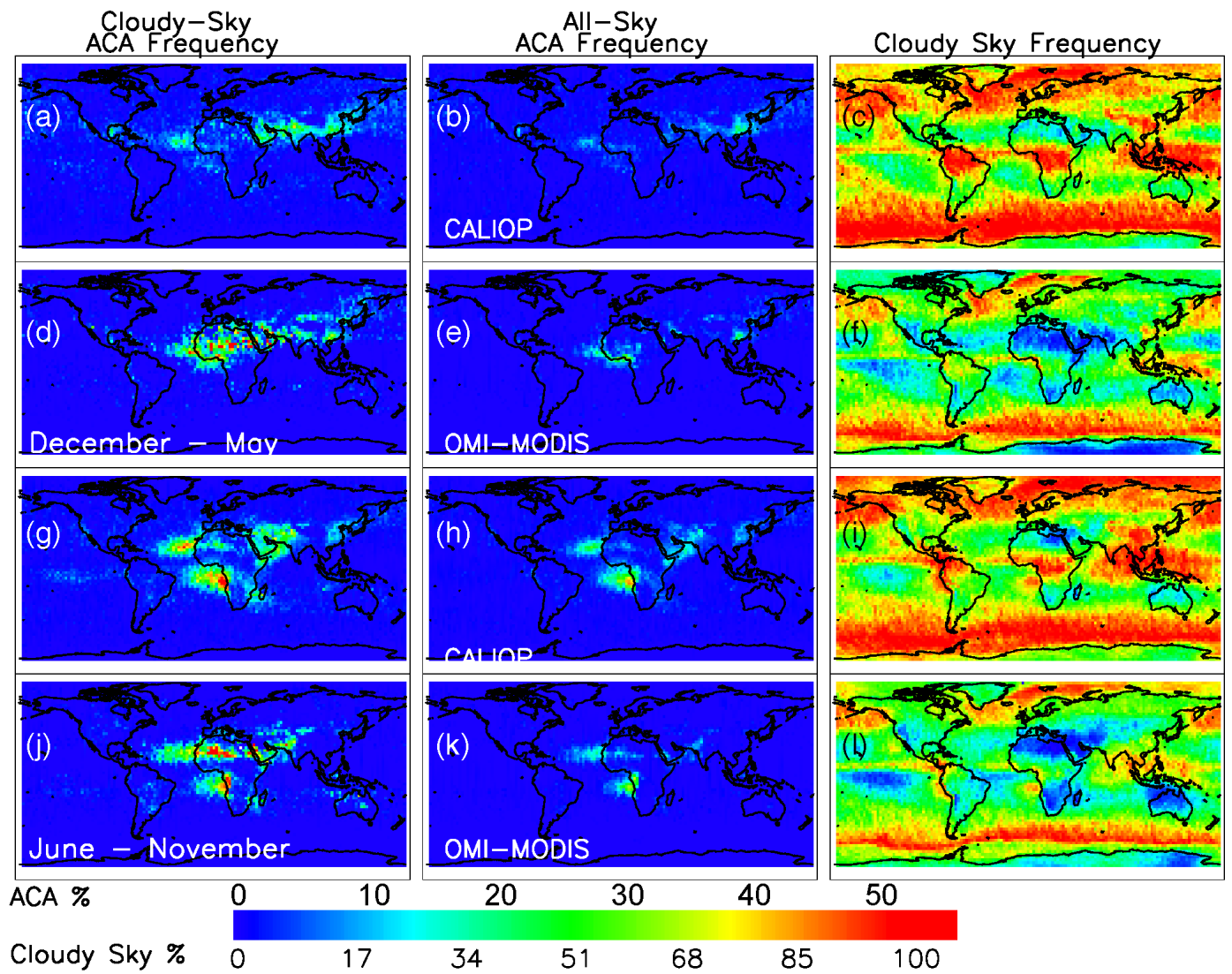

Figure 8. (a) Two-and-a-half-year (June 2006 to November 2008) daytime CALIOP cloudy-sky ACA frequency during the December through May period, using the collocated OMI-MODIS-CALIOP data set (defined in Table 1). (b) The same as (a) but for the all-sky CALIOP ACA frequency. (c) CALIOP cloudy-sky frequency, which is defined as the number of collocated CALIOP observations with COD $>0$ over the total number of collocated CALIOP observations. (d-f) Similar to (a-c) but using the OMI-MODIS-based method (defined in Table 1). It should be noted that the cloudy-sky frequency from the OMI-MODIS technique is defined as the number of observations with cloud fraction equal to 1 divided by the total number of observations (defined in Table 1). Panels ( $\mathbf{g}-\mathbf{j}$ ) depict the same information as (a-f) except for the June-November (2006-2008) period.

deficiencies in the OMI data products. As will be described below, we further investigate several aspects of the observed increase in interannual variability in the OMI-derived daytime cloudy-sky global ACA frequency.

Given the unexpected monotonic increase in global ACA frequency derived using OMI AI data over the course of our study, we examine the interannual variability in the OMI daytime cloudy-sky ACA frequency more closely. Figure 10 indicates a near-zero increase in the seasonal averages during the first few years of the study, with frequencies increasing at a rate of roughly $0.3-0.4 \%$ per year starting in 2009 . This time period coincides with the start of OMI data loss due to row anomalies, as mentioned above, leading us to further investigate this as a possible reason for the increase in the observed OMI cloudy-sky ACA frequency. Note that we detected data loss while collocating OMI and CALIOP data sets and found no collocated pixels after 2008, a possible sign that the data loss is likely affecting OMI nadir-viewing pixels. This is illustrated in Fig. 11a, which depicts a single swath of OMI AI over the African continent on 1 August 2007 where only OMI pixels with valid AI are shown. The data loss affected a large portion of the OMI AI data near the nadir regions of each OMI AI swath, as shown from a swath on 1 June 2009 (Fig. 11b).

Given that the data loss affects mostly nadir-viewing OMI pixels, OMI AI are evaluated as a function of the OMI sensor's viewing zenith angle (VZA) shown in Fig. 12. All OMI AI pixels for one year (2007) are averaged into $1^{\circ}$ VZA bins. Averaged OMI AI values at the edge of the swath are generally higher by about one AI unit than retrievals taken near the center of the swath. Thus, our analysis, which examines interannual variability in the OMI-derived ACA frequency, is compromised due to viewing geometry bias impacting later years of the OMI aerosol products. The remainder of the paper will focus solely on year-to-year variation derived from CALIOP ACA frequencies, and no further discussion of OMI AI frequencies will be carried out. 


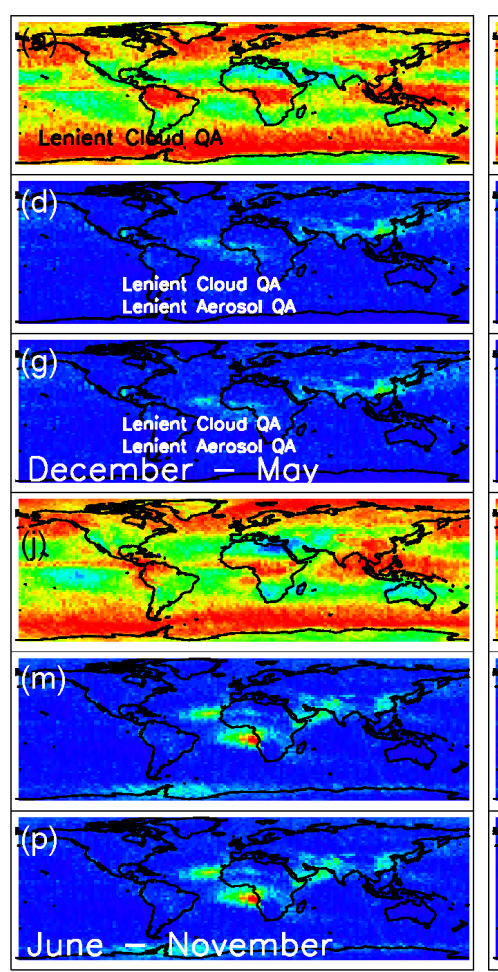

ACA \%

8
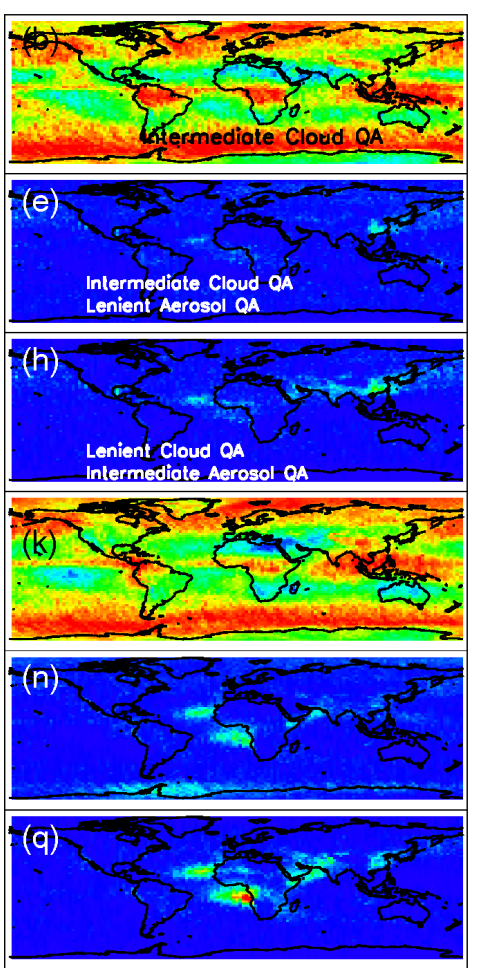

16
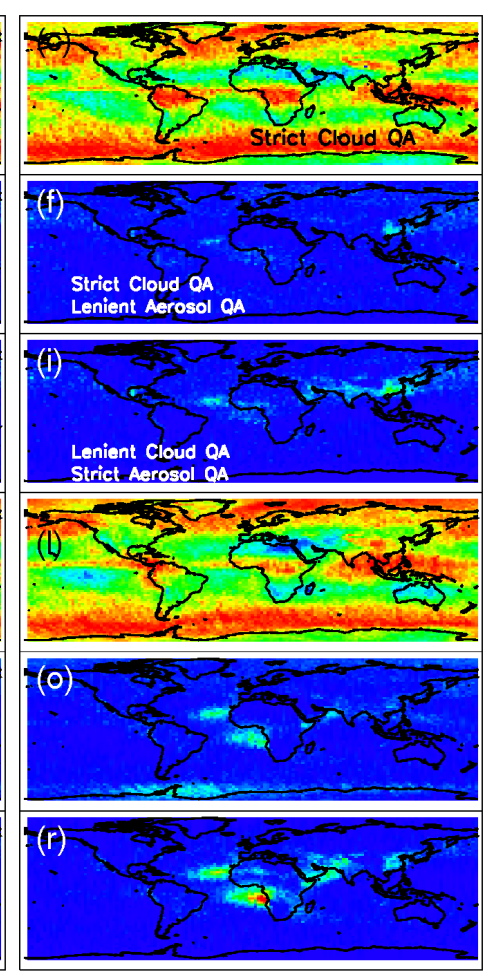

$24 \quad 32$

Cloudy Sky \% 17

51

68

85

Figure 9. (a) Two-and-a-half-year (June 2006 to November 2008) daytime CALIOP cloudy-sky frequency during the December through May period, using the collocated OMI-MODIS-CALIOP data set with the application of the most lenient cloud QA. Panels (b, c) depict the same information as Fig. 9A but now using intermediate and strict cloud QA settings, respectively. (d) Depicts the all-sky frequency using the same data set as Fig. 9A, now using lenient cloud and aerosol QAs. Panels (e, f) Depict the same information as (d) but varying the cloud QA to intermediate and strict. (g-i) Similar to $(\mathbf{d}-\mathbf{f})$ but holding the lenient cloud QA while varying the aerosol QA from lenient to intermediate and strict, respectively. Panels (j-r) depict the same information as (a-i) but for the June to November period (2006-2008).

Next, AERONET AOD data are used to identify possible bias in the CALIOP lidar due to potential signal deterioration in the instrument. Figure 13 depicts the year-to-year variation in the clear-sky AOD derived using collocated CALIOPAERONET data over all coastal and island AERONET stations (Zhang and Reid, 2006). The interannual variability in global AOD similar to those for the collocated AERONET and CALIOP data as shown in Fig. 13 seems to suggest that potential deterioration issues from CALIOP are rather insignificant to our ACA study.

\section{Sensitivity study}

We next investigate the impact that our noise floor thresholds for overlying CALIOP AOD and/or underlying COD exhibit on derived global CALIOP cloudy-sky ACA frequency. All CALIOP cloud and aerosol layer data sets are reprocessed such that the following conditions are met: (a) the underlying COD is greater than 0.3 and 2.5 , respectively, (b) the AOD of the above-cloud aerosol plume is greater than 0 , and (c) both conditions (a) and (b) are true. Passive-based radiance retrievals have been shown to lack sensitivities to optically thin cloud detection for optical depths less 0.3 (Sassen and Cho, 1992; Ackerman et al., 2008; Holz et al., 2008). Thus, restricting the CALIOP COD to this threshold offers a more direct comparison of CALIOP- and OMI-based ACA frequencies. However, given that this range of optical depth corresponds to relatively high cirrus clouds, for which little contribution to the overall sample is expected, and broken low-level liquid-phase clouds that are biased to ambiguously low values from signal aggregation effects in the $5 \mathrm{~km}$ product (Leahy et al., 2012; Campbell et al., 2015), this higher threshold provides a more representative basis for evaluation. We re-compute the monthly global mean cloudy-sky frequency for each of the CALIOP-constrained samples defined above during both daytime and nighttime. The interannual variability in global cloudy-sky ACA frequency derived from CALIOP is shown in Fig. 14. Corresponding sample sizes and mean global frequencies are shown in Table 2. 


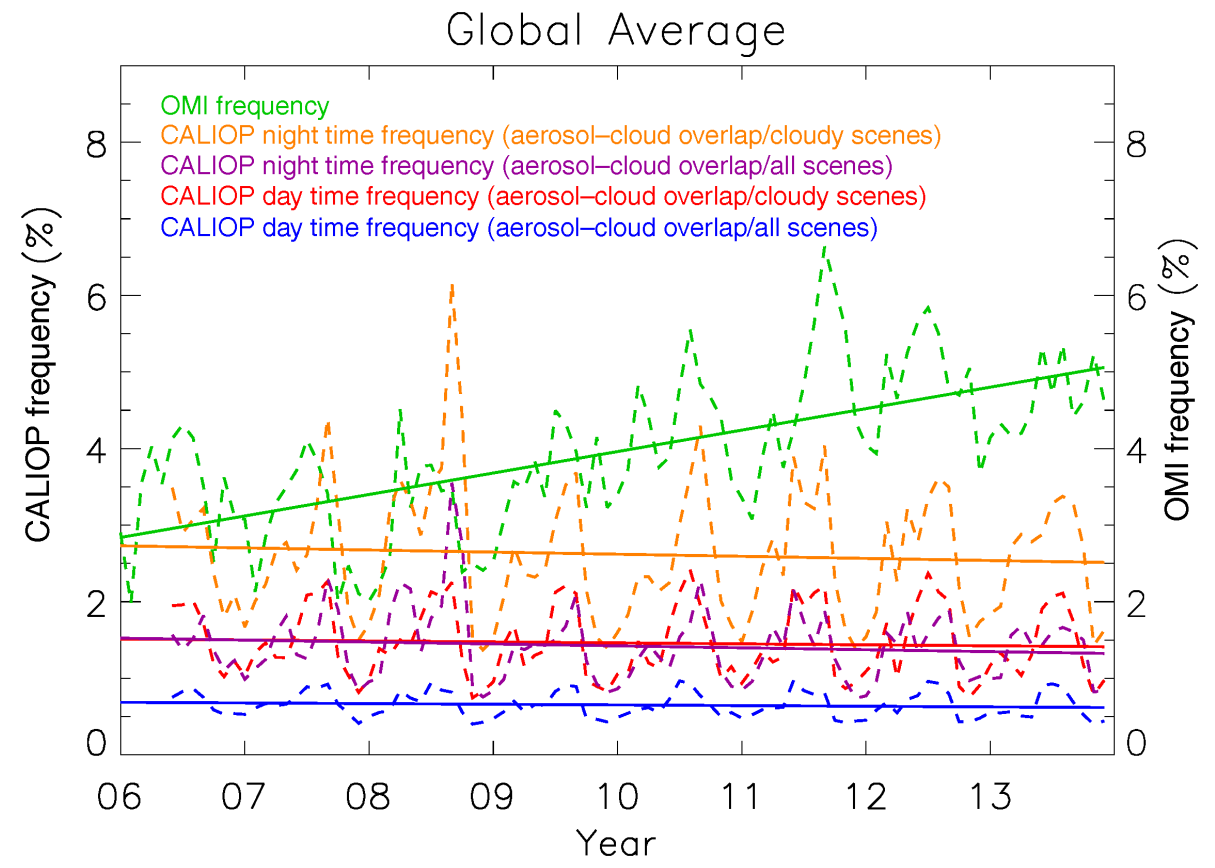

Figure 10. Monthly averaged global ACA frequencies derived using the OMI-MODIS-based method (green) as well as the CALIOP-based method as described in the text. The corresponding baseline thresholds are applied to both CALIOP and OMI data. Dashed lines represent monthly variations in ACA frequencies and the solid lines represent the yearly ACA frequency trends: OMI daytime cloudy-sky frequency is shown in green, CALIOP nighttime cloudy-sky frequency is orange, CALIOP nighttime all-sky frequency is purple, CALIOP daytime cloudy-sky frequency is red, and CALIOP daytime all-sky frequency is blue.
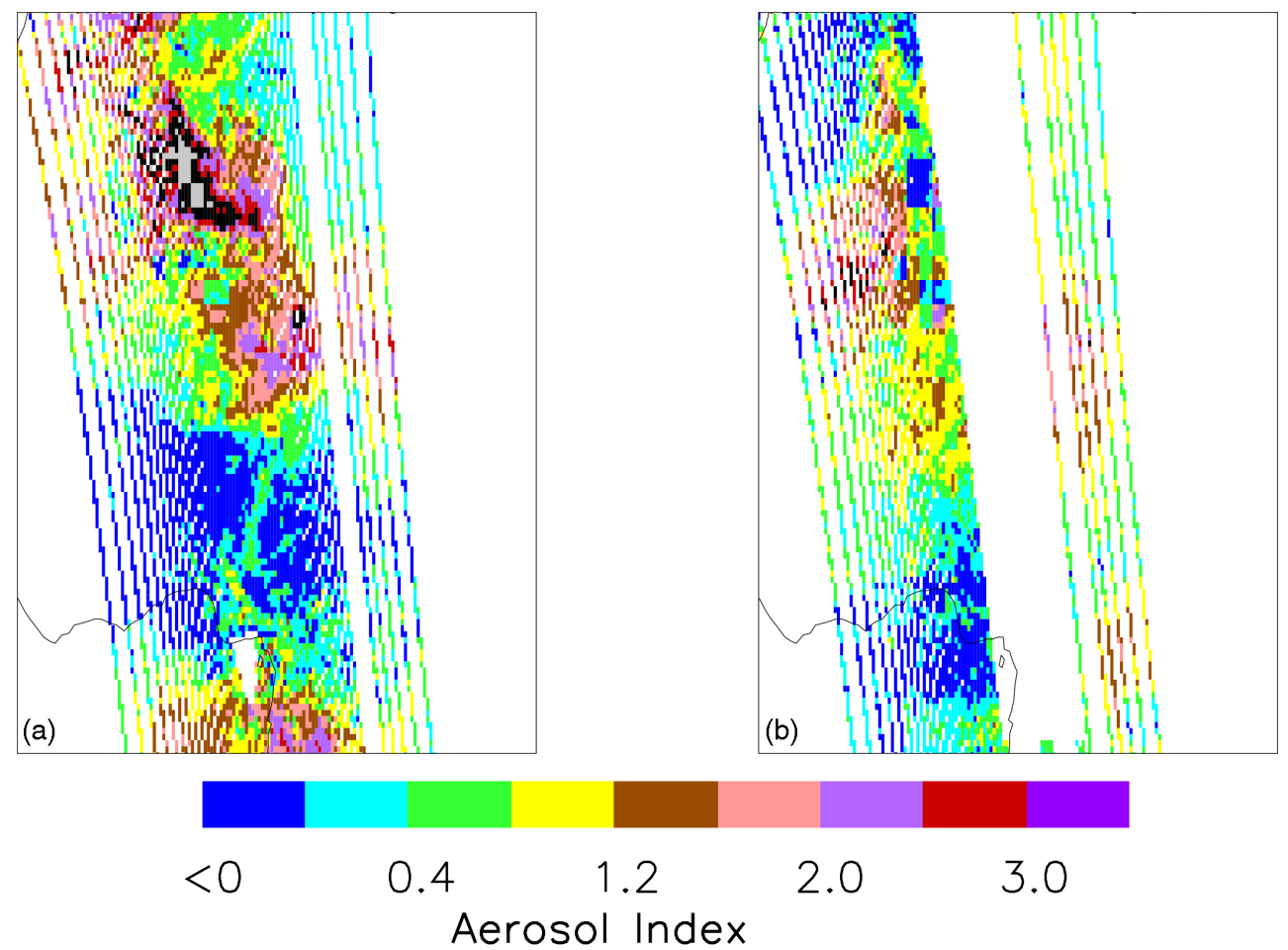

Figure 11. (a) A single swath from OMI over northern Africa on August 12007 before the significant data loss reported in all OMI aerosol products. (b) A single OMI AI swath over the same region as (a) on 1 June 2009 which is affected by the significant data loss. 


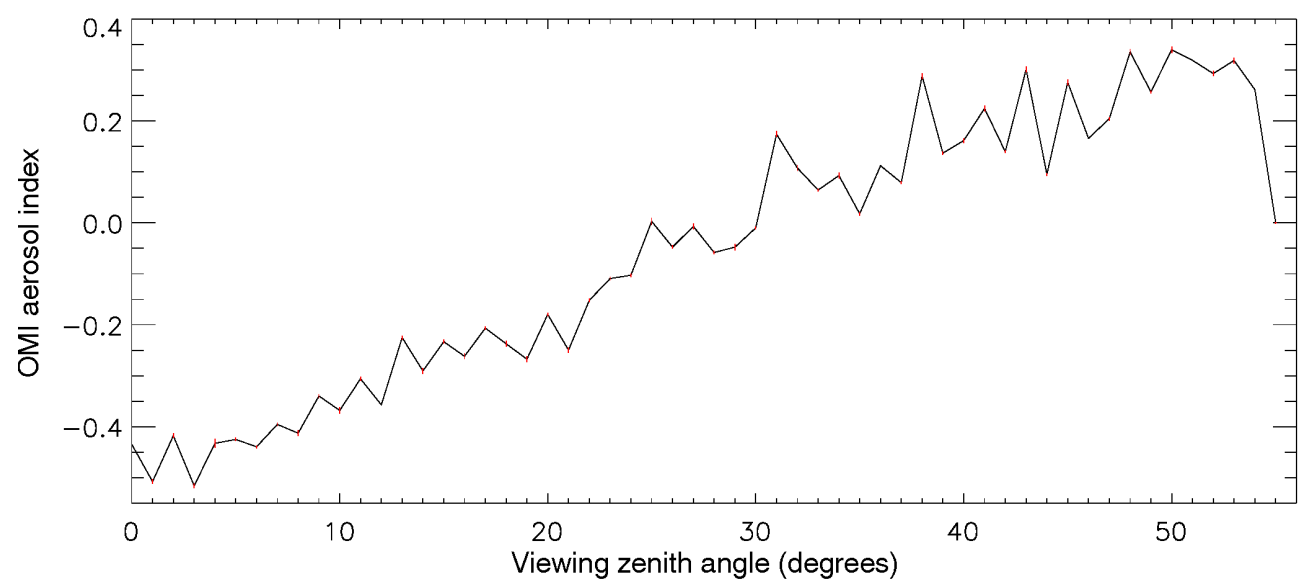

Figure 12. The OMI AI as a function of the sensor's viewing zenith angle (VZA). All OMI AI data over the course of a year (2007) were binned into $1^{\circ}$ VZA increments. The red vertical bars represent the $95 \%$ confidence interval for each $1^{\circ}$ bin.

Table 2. Global cloudy-sky relative frequency and data counts for the sensitivity test carried out in Sect. 5. Aerosol and cloud layers retrieved with "intermediate" or "strict" QA metrics are considered in this analysis. A total of five different threshold tests are applied to both day- and nighttime CALIOP cloud and aerosol layer products.

\begin{tabular}{|c|c|c|}
\hline & Day & Night \\
\hline Total cloudy scenes (column COD > 0/0.3/2.5) & $100028240 / 54801072 / 28559920$ & $91828232 / 52634300 / 25897344$ \\
\hline \multicolumn{3}{|c|}{ Data counts/mean global ACA relative frequency } \\
\hline $\mathrm{COD}>0 \& \mathrm{AOD}>0$ & $1193048 / 1.79 \%$ & $3368351 / 4.5 \%$ \\
\hline $\mathrm{COD}>0.3 \& \mathrm{AOD}>0$ & $789652 / 2.0 \%$ & $2795442 / 6.1 \%$ \\
\hline $\mathrm{COD}>2.5 \& \mathrm{AOD}>0$ & $556097 / 2.5 \%$ & $2091310 / 8.09 \%$ \\
\hline $\mathrm{COD}>0.3 \& \mathrm{AOD}>0.015$ & $597917 / 1.63 \%$ & $1516547 / 3.54 \%$ \\
\hline $\mathrm{COD}>2.5 \& \mathrm{AOD}>0.015$ & $420778 / 2.0 \%$ & $1167569 / 4.52 \%$ \\
\hline $\mathrm{COD}>0 \& \mathrm{AOD}>0.015$ & $904892 / 1.46 \%$ & $1765620 / 2.6 \%$ \\
\hline
\end{tabular}

In comparison with the unfiltered data from the daytime (solid red) and nighttime (dotted red) analyses, the various threshold techniques, including the filtering of CALIOP ACAOD according to our floor noise, correspond to significant variance in our results. However, all sensitivity tests seem to show the same slightly negative trend in cloudy-sky ACA frequency. However, those ACA events found over optically thicker clouds (COD > 2.5) seem to show more of a null interannual variability over time rather than a slightly negative interannual variability in the CALIOP global ACA frequency. The COD threshold tests raises the daytime mean global cloudy-sky frequency from 1.8 to 2.0 and $2.5 \%$ for the 0.3 and $2.5 \mathrm{COD}$ thresholds, respectively. This corresponds to a reduction in the sample size of approximately 0.4 $(\mathrm{COD}<0.3)$ and $0.6(\mathrm{COD}<2.5)$ million scenes when compared with the unfiltered methods. During the nighttime analysis, the global mean cloudy-sky frequency is changed from 4.5 to 6.1 and $8.1 \%$, respectively, while data counts change to 2.8 and 2.1 million globally for the corresponding nighttime COD threshold tests. Setting a noise floor threshold on the AOD reduces mean global cloudy-sky ACA frequencies by 0.33 and $1.9 \%$ for day- and nighttime analyses, respectively, corresponding to a reduction of global data counts of 0.3 and 1.6 million scenes. After screening out millions of samples during this sensitivity analysis, the same near-zero or decreasing trend is found for CALIOP ACA frequencies, which is indication that neither cloud or aerosol thresholds, or lack thereof, have a major impact on the interannual variability in global CALIOP cloudy-sky ACA frequency.

\section{Regional year-to-year variation analysis}

A regional analysis of cloudy-sky ACA frequency is also conducted, consistent with methods described above for global analysis. Regional analyses were chosen over regions of high ACA frequency, as indicated in Fig. 3. The nine regions of interest, shown in Table 3 and indicated by the red boxes in Fig. 3, are northern Saharan Africa, southern Africa, Southeast Asia, China, the Middle East, South America, India, North America, and the Southern Ocean. Figure 15 shows the regional cloudy-sky deseasonalized ACA frequency for CALIOP daytime (blue) and nighttime (aqua 


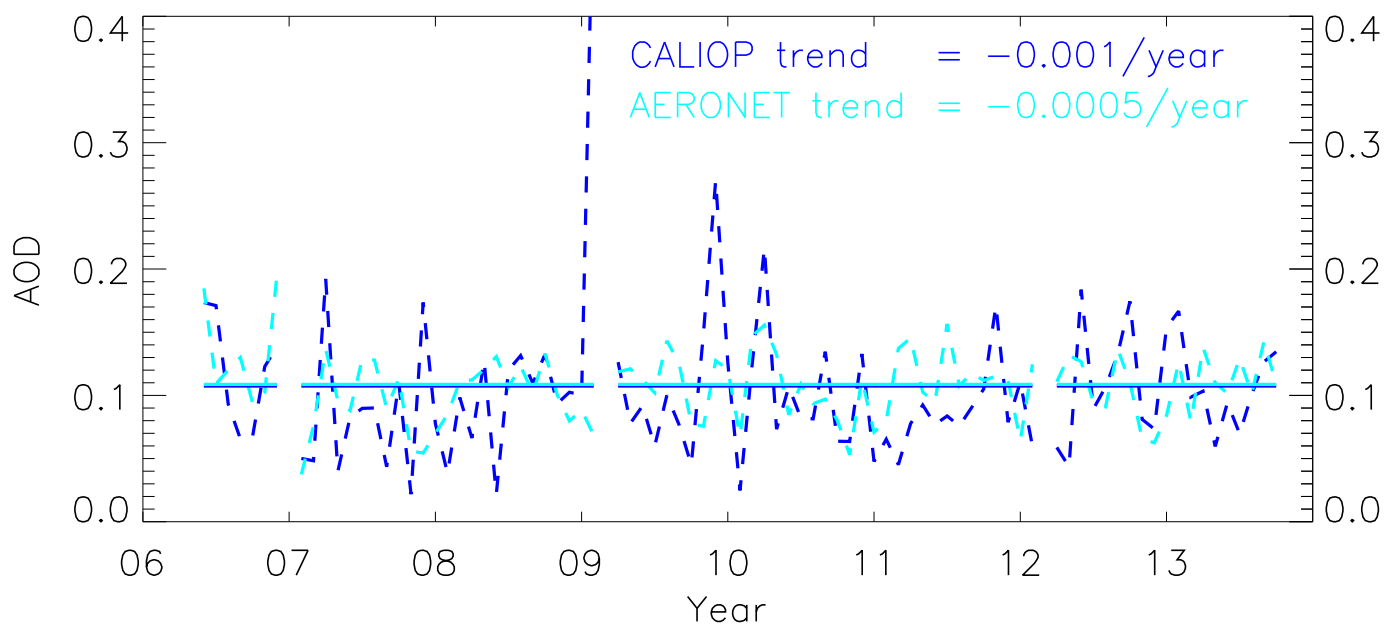

Figure 13. Monthly averaged over ocean clear-sky AODs derived from collocated CALIOP and AERONET data. CALIOP retrievals within $0.3^{\circ}$ latitude and longitude and $\pm 30 \mathrm{~min}$ of the corresponding AERONET station and observation are considered collocated. AERONET and CALIOP AODs above 0.2 and 0.6, respectively, are not included in order to avoid high aerosol loading cases and exclude noisy CALIOP data.

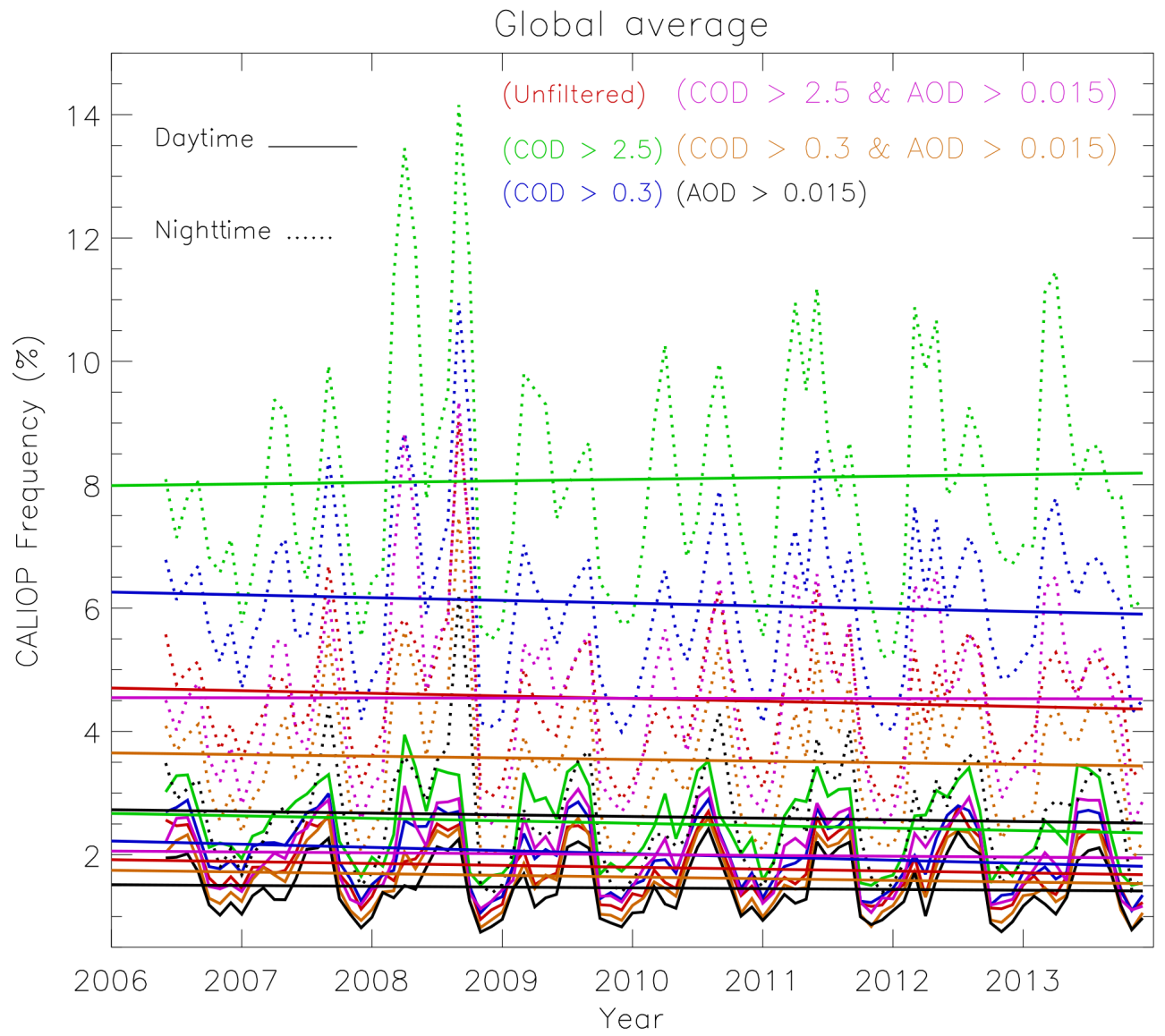

Figure 14. Monthly averaged global CALIOP cloudy-sky frequencies after applying several different threshold techniques to both day- and nighttime data. The solid lines show the daytime scenario for each respective case, while the dotted lines show the nighttime observations for each case. 

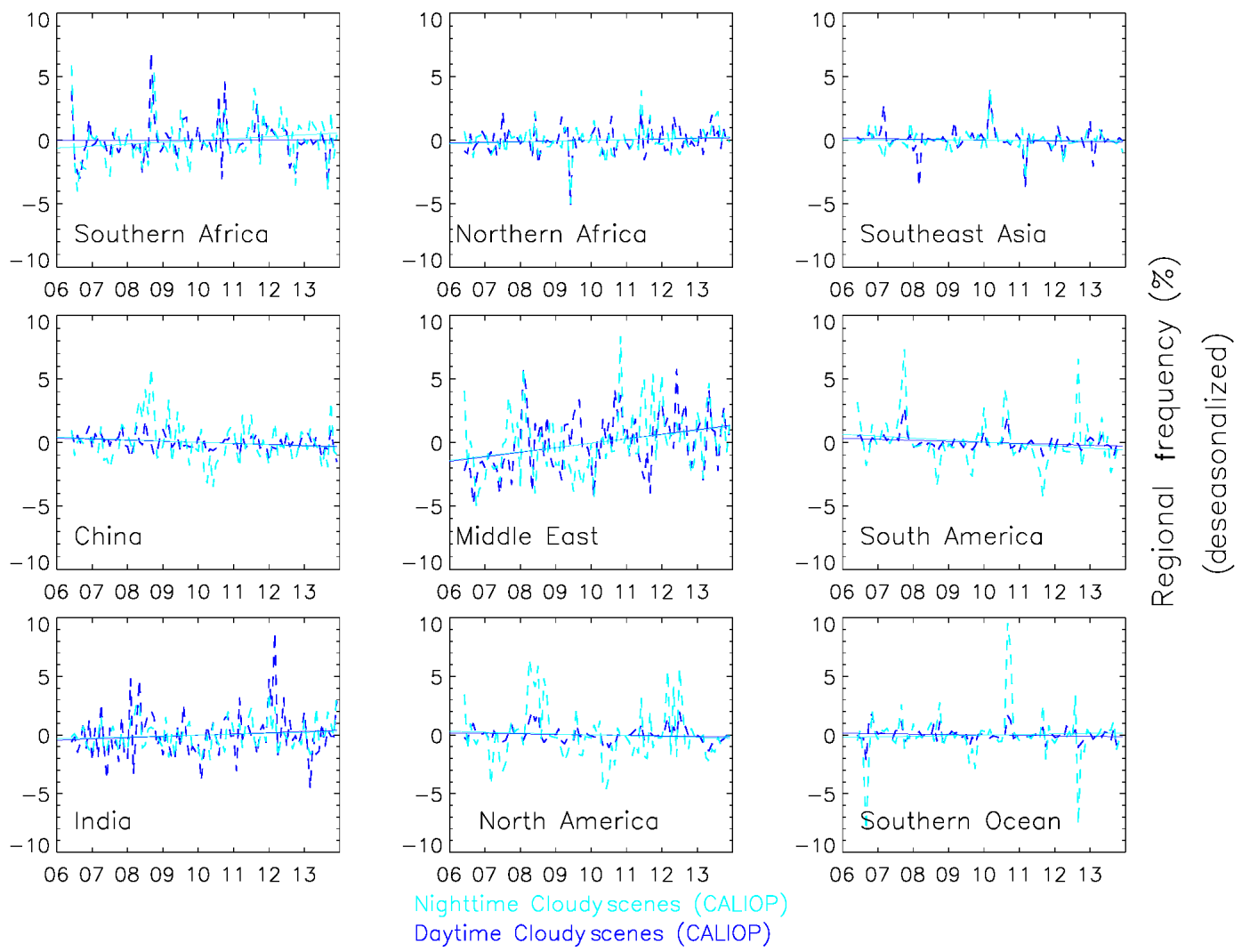

Figure 15. The deseasonalized monthly and regionally averaged cloudy-sky frequency of ACA occurrences for the nine different regions outlined in Fig. 3 and explained in Table 3. The dashed lines show the monthly frequency over the regions and the solid lines show the trend lines computed for each region, with the $x$ axis representing the year of the study. The CALIOP nighttime analysis is shown in aqua marine and the daytime analysis is shown in dark blue.

marine) analyses, along with linear regression lines (described earlier for the global analysis). Positive interannual variability in the cloudy-sky ACA frequency is found over the Middle East and India for both daytime and nighttime. In contrast, decreasing interannual variability in the cloudy-sky ACA frequency is found over China and South America for both daytime and nighttime. All other regions correspond to a negligible change in cloudy-sky ACA frequency during the study period.

A regional analysis of variation in cloud coverage over time is also conducted in order to investigate whether the observed increases in ACA frequency over time are a result of cloud coverage or aerosol loading. Positive AOD trends are observed from both regions (Zhang and Reid, 2010; Hsu et al., 2012). Cloud cover frequency exhibits an insignificant trend over India, indicating that the ACA frequency increase may be due to aerosol loading increase over the region. The observed increase in cloudy-sky ACA frequency over the Middle East, however, may be also due to the aerosols, as a slight decrease cloud coverage frequency is observed over time over this region. Interannual variability and its significance are also calculated for each of the regional and global analyses shown in Table 3 using methods described by Weatherhead et al. (1998). As is apparent from Table 3, none of the trends are statistically significant (i.e., trend significance $>2$ ) with a confidence interval of $95 \%$. Applying methods described in Weatherhead et al. (1998), we determine that an ACA data record spanning 37 and 36 years is needed to detect a $1 \%$ yearly change with $95 \%$ confidence in cloudy-sky ACA frequency for day- and nighttime, respectively.

Interannual variability for both ACAOD and cloud-free AOD are also calculated globally and for all regions shown in Table 3. Globally, the interannual variabilities of clear-sky AOD and ACAOD are slightly positive, while the ACA frequency is negative during both day and night. Regions corresponding to a negative trend of all three parameters (ACA frequency, ACAOD, and clear-sky AOD) include Southeast Asia (nighttime) and South America (nighttime). The Middle East (day and night) and India (day) regions exhibit positive trends for all three parameters. The remaining regions exhibit a combination of positive, negative, or near-zero trends in all three parameters. 
Table 3. Seven-and-a-half-year above-cloud aerosol cloudy-sky frequency, ACAOD, and clear-sky AOD interannual variability analysis for the selected target regions. Aerosol and cloud layers retrieved with "intermediate" or "strict" QA metrics are considered in this analysis. Yearly variation for the entire globe is also included. For each region, interannual variability (frequency change per year) for the three parameters - the ACA cloudy-sky frequency, ACAOD, and clear-sky AOD values - is reported. Note that the interannual variability for clear-sky AODs is estimated using $100 \%$ cloud-free data from the CALIOP cloud and aerosol layer products.

\begin{tabular}{|c|c|c|c|c|c|c|}
\hline Region & Latitude $\left({ }^{\circ}\right)$ & Longitude $\left({ }^{\circ}\right)$ & $\begin{array}{l}\text { Slope/per year } \\
\text { (CALIOP day- } \\
\text { time) }(\%)\end{array}$ & $\begin{array}{l}\text { Trend significance } \\
\text { CALIOP daytime } \\
\left(\frac{\omega^{\prime}}{\sigma_{\omega^{\prime}}}\right)\end{array}$ & $\begin{array}{l}\text { Slope/per year } \\
\text { (CALIOP nighttime) } \\
(\%)\end{array}$ & $\begin{array}{l}\text { Trend significance } \\
\text { CALIOP nighttime } \\
\left(\frac{\omega^{\prime}}{\sigma_{\omega^{\prime}}}\right)\end{array}$ \\
\hline \multicolumn{7}{|c|}{ ACA cloudy-sky frequency (\%)/above-cloud aerosol AOD/clear-sky AOD } \\
\hline Southern Africa & $37^{\circ} \mathrm{S}$ to $5^{\circ} \mathrm{N}$ & $30^{\circ} \mathrm{W}$ to $30^{\circ} \mathrm{E}$ & $\begin{array}{l}0.007 / \\
-0.001 / \\
-0.0004\end{array}$ & $\begin{array}{l}0.009 / \\
0.18 / \\
0.04\end{array}$ & $\begin{array}{l}0.148 / \\
0.0005 / \\
0.0009\end{array}$ & $\begin{array}{l}0.159 / \\
0.067 / \\
0.08\end{array}$ \\
\hline Northern Africa & 5 to $35^{\circ} \mathrm{N}$ & $70^{\circ} \mathrm{W}$ to $25^{\circ} \mathrm{E}$ & $\begin{array}{l}0.05 / \\
-0.0006 / \\
-0.001\end{array}$ & $\begin{array}{l}0.116 / \\
0.035 / \\
0.07\end{array}$ & $\begin{array}{l}0.07 / \\
-0.0001 / \\
-0.002\end{array}$ & $\begin{array}{l}0.133 / \\
0.005 / \\
0.09\end{array}$ \\
\hline Southeast Asia & 10 to $25^{\circ} \mathrm{N}$ & 90 to $150^{\circ} \mathrm{E}$ & $\begin{array}{l}-0.04 / \\
0.004 / \\
-0.002\end{array}$ & $\begin{array}{l}0.080 / \\
0.17 / \\
0.1\end{array}$ & $\begin{array}{l}-0.010 / \\
-0.0012 / \\
-0.0004\end{array}$ & $\begin{array}{l}0.026 / \\
0.07 / \\
0.02\end{array}$ \\
\hline China & 30 to $55^{\circ} \mathrm{N}$ & 110 to $160^{\circ} \mathrm{E}$ & $\begin{array}{l}-0.084 / \\
0.0006 / \\
0.0009\end{array}$ & $\begin{array}{l}0.238 / \\
0.090 / \\
0.05\end{array}$ & $\begin{array}{l}-0.10 / \\
-0.0006 / \\
0.0002\end{array}$ & $\begin{array}{l}0.088 / \\
0.10 / \\
0.008\end{array}$ \\
\hline Middle East & 10 to $40^{\circ} \mathrm{N}$ & 30 to $55^{\circ} \mathrm{E}$ & $\begin{array}{l}0.36 / \\
0.004 / \\
0.006\end{array}$ & $\begin{array}{l}0.239 / \\
0.15 / \\
0.16\end{array}$ & $\begin{array}{l}0.339 / \\
0.004 / \\
0.005\end{array}$ & $\begin{array}{l}0.238 / \\
0.09 / \\
0.13\end{array}$ \\
\hline South America & $20^{\circ} \mathrm{S}$ to $10^{\circ} \mathrm{N}$ & 105 to $60^{\circ} \mathrm{W}$ & $\begin{array}{l}-0.078 / \\
0.0018 / \\
-0.0016\end{array}$ & $\begin{array}{l}0.189 / \\
0.18 / \\
0.12\end{array}$ & $\begin{array}{l}-0.157 / \\
-0.0002 / \\
-0.0019\end{array}$ & $\begin{array}{l}0.109 / \\
0.03 / \\
0.09\end{array}$ \\
\hline India & 0 to $30^{\circ} \mathrm{N}$ & 60 to $85^{\circ} \mathrm{E}$ & $\begin{array}{l}0.10 / \\
0.001 / \\
0.0084\end{array}$ & $\begin{array}{l}0.106 / \\
0.08 / \\
0.20\end{array}$ & $\begin{array}{l}0.08 / \\
-0.0035 / \\
0.010\end{array}$ & $\begin{array}{l}0.110 / \\
0.064 / \\
0.19\end{array}$ \\
\hline North America & 20 to $60^{\circ} \mathrm{N}$ & 160 to $110^{\circ} \mathrm{W}$ & $\begin{array}{l}-0.05 / \\
0.0005 / \\
0.00002\end{array}$ & $\begin{array}{l}0.082 / \\
0.06 / \\
0.003\end{array}$ & $\begin{array}{l}-0.074 / \\
-0.0005 / \\
-0.0003\end{array}$ & $\begin{array}{l}0.045 / \\
0.10 / \\
0.04\end{array}$ \\
\hline Southern Ocean & 40 to $12^{\circ} \mathrm{S}$ & 35 to $115^{\circ} \mathrm{E}$ & $\begin{array}{l}-0.04 / \\
0.0004 / \\
0.0012\end{array}$ & $\begin{array}{l}0.120 / \\
0.083 / \\
0.29\end{array}$ & $\begin{array}{l}0.05 / \\
0.0004 / \\
0.0008\end{array}$ & $\begin{array}{l}0.037 / \\
0.078 / \\
0.21\end{array}$ \\
\hline Global & & & $\begin{array}{l}-0.004 / \\
0.0004 / \\
0.0006\end{array}$ & $\begin{array}{l}0.049 / \\
0.16 / \\
0.13\end{array}$ & $\begin{array}{l}-0.02 / \\
0.0004 / \\
0.0007\end{array}$ & $\begin{array}{l}0.05 / \\
0.15 / \\
0.18\end{array}$ \\
\hline
\end{tabular}

\section{Conclusions}

Using Cloud-Aerosol Lidar with Orthogonal Polarization (CALIOP) layer products and collocated Ozone Monitoring Instrument (OMI) aerosol products and Aqua Moderate Resolution Imaging Spectroradiometer (MODIS) cloud products data from June 2006 to December 2013, spatial distributions, including global and regional variabilities, of above-cloud aerosol (ACA) events are studied and compared. Activebased profiling is considered an optimal means for identifying ACA occurrence. OMI identification is restricted to ultraviolet (UV)-absorbing ACA events (i.e., smoke), in contrast, through the aerosol index (AI) parameter. However, the relatively wide field of view of the paired OMI-MODIS data sets provides greater data volume overall, which serves as a relatively well-characterized reference for comparing with CALIOP

The primary findings of this study are as follows:

1. Baseline values for passive-based OMI AI and activebased CALIOP above-cloud aerosol optical depth (ACAOD) are established in order to distinguish background noise from signal due to significant ACA events such as dust outbreaks and biomass burning. The "noise floor" for OMI AI and CALIOP is applied to their respective data sets during processing. However, caution should be exercised when using these baselines, as they are an approximation and will vary depending on ancillary observational parameters for OMI and day versus nighttime sensitivity for CALIOP. 
2. Despite fundamental differences in spatial and vertical samplings, as well as sensitivity to ACA aerosol types, both OMI- and CALIOP-based techniques broadly resolve consistent global distributions of cloudy-sky ACA frequency. For example, both capture ACA events over the northwest coast of Africa and the Arabian Peninsula during the December-May period, as well as over the northwest, southwest, and southeast coast of Africa, the Arabian Peninsula, and the Arabian Sea during the June-November period. Still, discrepancies, as expected, are present. For example, daytime cloudy-sky ACA frequencies of up to $10 \%$ are found from CALIOP over Southeast Asia during the June-November period while such ACA events are non-existent using the OMIbased method. Over northern Africa, cloudy-sky ACA frequencies of around $20-30 \%$ are reported for both periods from the OMI-based method, yet such events are largely undetected by the CALIOP-based method. We suspect that heavy dust plumes may be misidentified as clouds by the passive-based method, thus causing an unexpected rise in the passive-based derived cloudy-sky ACA frequency over that region.

3. The differences between the OMI- and CALIOP-based daytime cloudy-sky ACA frequencies are explored using a collocated OMI-MODIS-CALIOP data set for the period of June 2006 to November 2008. Our analysis shows that the difference in cloud detectability between the MODIS and CALIOP instruments, as well as the QA flags applied, are the major reasons for the differences. Although the OMI-MODIS-based method is only sensitive to UV-absorbing aerosols and the CALIOPbased method is capable of detecting ACA events of all aerosol types, we did not find this to be one of the major reasons for the difference in ACA frequencies.

4. CALIOP nighttime data exhibit slightly larger distributions and a 10-20\% greater cloudy-sky ACA frequency annually in comparison with daytime. This may be due the subsidence of the planetary boundary layer at night, influencing frequencies of low-cloud formation, as well as the impact of a higher signal-to-noise ratio in CALIOP data sets for subsequent level 2 analysis partly controlled for in our study by applying the noise floor. To the latter point, previous study has shown relative stability between day/night CALIOP aerosol products (Campbell et al., 2012). However, the implicit effect on the vertical distribution of aerosol occurrence was not specifically investigated. More detailed study is needed to reconcile this finding.

5. We find a near-zero negligible slope in the global CALIOP cloudy-sky and all-sky ACA frequencies. However, OMI-MODIS cloudy-sky daytime ACA frequencies show an increase of $\sim 0.3-0.4 \%$ year $^{-1}$ since 2009 , possibly due to a significant loss in the OMI data starting in 2009 mostly for nadir-viewing pixels. Investigation of the relationship between OMI aerosol index (AI) and satellite viewing zenith angle, suggests a viewing angle dependency of OMI AI. Considering that OMI $\mathrm{AI}$ increases near the edge of the viewing swath, it is possible that the overall increase in ACA frequency is due to the significant loss of OMI AI data during later years of the study.

6. Changes in the cloudy-sky global ACA frequency and data counts ranging from 2 to $4 \%$ and 1 to 3 million, respectively, are found as a result of applying a variety of thresholds to the ACAOD and/or underlying cloud optical depth (COD) during sensitivity analysis. COD thresholds of 0.3 and 2.5 filter high cirrus clouds and non-contiguous low-level water clouds, respectively. CALIOP data are further reprocessed with no restriction on the ACAOD. Most threshold tests show a reduction in global ACA frequencies; however, those ACA events located over optically thick clouds (COD $>2.5$ ) show a near-zero slope in the ACA frequency variability. However, a significant change over time in CALIOP global day or nighttime ACA frequency is not apparent.

7. Globally, clear-sky AOD and ACAOD temporal variations are slightly positive, while cloudy-sky ACA frequency exhibits a slightly negative interannual variability in both day- and nighttime. Some select regions examined globally, selected for their relatively high ACA frequency overall, exhibit a consistent interannual variability in all three parameters. For example, statistically significant increases in clear-sky AOD are found over India and the Middle East from various passivebased analysis (e.g., Zhang and Reid, 2010). Increases in cloudy-sky ACA frequencies are also found for the two regions for the study period of 2006-2013. Other regions exhibit agreement between some, but not all, parameters. However, neither the regional nor global trends of any of the three parameters are statistically significant. An ACA data record spanning at least 30 years is needed in order to report a $10 \%$ per decade change in ACA frequency with $95 \%$ confidence.

This study confirms that significant (i.e., resolvable with the techniques applied) ACA events occur with a frequency of $1-8 \%$ globally, and as high as $30-50 \%$ regionally, over some of the most ACA-abundant regions. The two complementary techniques applied to locate ACA events and derive global and regional distributions and both exhibit strengths and weaknesses. This study shows that, when used simultaneously, combined passive-active analysis can help present a more comprehensive analysis of ACA than a single-sensor analysis alone. However, the analysis strongly reinforces the use of active-based lidar profiling for distinguishing aerosol presence that perturbs passive-based column-integrated radiative parameters. The vertical distribution and optical prop- 
erties of aerosol and cloud layers are fundamental to accurate column radiative closure. The effects cloud-aerosol overlap can exhibit on cloud and aerosol property retrieval techniques demands some coordinated active/passive observation for ensuring clarity and limiting bias in top-of-atmosphere retrievals.

Due to the extensive spatial coverage and consistency of retrieved data sets from spaceborne instruments, trend analyses, as well as the need for consistent multi-sensor profiling, should become primary motivating factors behind mission design and life expectancy in orbit. Our analysis shows that, in a few decades, proper analysis of ACA trends will be possible through continuation of a CALIOP/OMIlike paradigm. Ultimately, this work, paired with AlfaroContreras et al. (2014) and others, has broadly conceptualized the ACA problem globally. Past studies have shown that ACA events represent a fundamental climate phenomenon on a global scale (Peters et al., 2011); thus ACA requires specific long-term monitoring. Trend analysis, then, will help in ultimately distinguishing this attribute, and thus whether or not ACA is simply noise or a radiatively significant process that is sensitive to changes in land use globally and a fluctuating frequency and distribution of elevated aerosol particles over time. Future satellite mission designs should emphasize extending the life of these instruments for application to environmental parameter interannual variability studies.

Acknowledgements. This research is funded through the support of the Office of Naval Research Code 322. R. Alfaro-Contreras is supported by NASA project NNX14AJ13G. J. R. Campbell acknowledges the support of NASA Interagency Agreement IAARPO201422 on behalf of the CALIPSO Science Team. We thank the AERONET program and their contributing principal investigators for collecting and maintaining the sun photometer data. CALIOP cloud and aerosol layer data were obtained from the Atmospheric Science Data Center. MODIS cloud data were obtained from the Goddard Space Flight Center Level 1 and atmospheric archive and distribution center system. The OMI aerosol data were obtained from the Goddard Earth Science Data Center and Information Service Center. We thank Abhay Devasthale, Karsten Peters, Hiren Jethva, and the two anonymous reviewers for their constructive comments and suggestions.

Edited by: P. Stier

\section{References}

Ackerman, S. A., Strabala, K. I., Menzel, W. P., Frey, R. A, Moeller, C. C., and Gumley, L. E.: Discriminating clear sky from clouds with MODIS, J. Geophys. Res., 103, 32141-32157, doi:10.1029/1998JD200032, 1998.

Ackerman, S. A., Holz, R. E., Frey, R. E., Eloranta, R. W., Maddux, B., and McGill, M. J.: Cloud detection with MODIS: Part II. Validation, J. Atmos. Ocean. Tech., 25, 1073-1086, 2008.
Alfaro-Contreras, R., Zhang, J., Reid, J. S., Campbell, J. R., and Holz, R. E.: Evaluating the impact of aerosol particles above cloud on cloud optical depth retrievals from MODIS, J. Geophys. Res.-Atmos., 119, 5410-5423, doi:10.1002/2013JD021270, 2014.

Campbell, J. R., Tackett, J. L., Reid, J. S., Zhang, J., Curtis, C. A., Hyer, E. J., Sessions, W. R., Westphal, D. L., Prospero, J. M., Welton, E. J., Omar, A. H., Vaughan, M. A., and Winker, D. M.: Evaluating nighttime CALIOP $0.532 \mu \mathrm{m}$ aerosol optical depth and extinction coefficient retrievals, Atmos. Meas. Tech., 5, 2143-2160, doi:10.5194/amt-5-2143-2012, 2012.

Campbell, J. R., Vaughan, M. A., Oo, M., Holz, R. E., Lewis, J. R., and Welton, E. J.: Distinguishing cirrus cloud presence in autonomous lidar measurements, Atmos. Meas. Tech., 8, 435449, doi:10.5194/amt-8-435-2015, 2015.

Coddington, O. M., Plewskie, P., Redemann, J., Platnick, S., Russell, P. B., Schmidt, K. S., Gore, W. J., Livingston, J., Wind, G., and Vukicevic, T.: Examining the impact of overlying aerosols on the retrieval of cloud optical properties from passive remote sensing, J. Geophys. Res., 115, D10211, doi:10.1029/2009JD012829, 2010.

Devasthale, A. and Thomas, M. A.: A global survey of aerosol-liquid water cloud overlap based on four years of CALIPSO-CALIOP data, Atmos. Chem. Phys., 11, 1143-1154, doi:10.5194/acp-11-1143-2011, 2011.

Eck, T. F., Holben, B. N., Reid, J. S., Dubovik, O., Smirnov, A., O'Neill, N. T., Slutsker, I., and Kinne, S.: Wavelength dependence of the optical depth of biomass burning, urban and desert dust aerosols, J. Geophys. Res., 104, 31333-31349, doi:10.1029/1999JD900923, 1999.

Haywood, J. M.,Osborne, S. R., and Abel, S. J.: The effect of overlying absorbing aerosol layers on remote sensing retrievals of cloud effective radius and cloud optical depth, Q. J. Roy. Meter. Soc., 130, 779-800, doi:10.1256/qj.03.100, 2004.

Holben, B. N., Eck, T. F., Slutsker, I., Tanre, D., Buis, J. P., Setzer, A., Vermote, E., Reagan, J. A., Kaufman, Y. J., Nakajima, T., Lavenu, F., Jankowiak, I., and Smirnov, A.: AERONET - a federated instrument network and data archive for aerosol characterization, Remote Sens. Environ., 66, 1-16, 1998.

Holz, R. E., Ackerman, S. A., Nagle, F. W., Frey, R., Dutcher, S., Kuehn, R. E., Vaughan, M. A., and Baum, B.: Global Moderate Resolution Imaging and Spectroradiometer (MODIS) cloud detection and height evaluation using CALIOP, J. Geophys. Res., 113, D00A19, doi:10.1029/2008JD009837, 2008.

Hsu, N. C., Gautam, R., Sayer, A. M., Bettenhausen, C., Li, C., Jeong, M. J., Tsay, S.-C., and Holben, B. N.: Global and regional trends of aerosol optical depth over land and ocean using SeaWiFS measurements from 1997 to 2010, Atmos. Chem. Phys., 12, 8037-8053, doi:10.5194/acp-12-8037-2012, 2012.

Intergovernmental Panel on Climate Change (IPCC): The physical science basis, and contribution of working group I to the fourth assessment report of the IPCC 916, Cambridge University Press, 112-116, 2007.

Kacenelenbogen, M., Redemann, J., Vaughan, M. A., Omar, A. H., Russell, P. B., Burton, S., Rogers, R. R., Ferrare, R. A., and Hostetler, C. A.: An evaluation of CALIOP/CALIPSO's aerosol-above-cloud detection and retrieval capability over North America, J. Geophys. Res.-Atmos., 119, 230-244, doi:10.1002/2013JD020178, 2014. 
Kahn, R. A., Garay, M. J., Nelson, D. L., Levy, R. C., Bull, M. A., Diner, D. J., Martonchik, J. V., Hansen, E. G., Remer, L. A., and Tanre, D.: Response to "Toward unified satellite climatology and aerosol properties. 3. MODIS versus MISR AERONET”, J. Quant. Spectrosc. Ra., 112, 901-909, doi:10.1016/j.jqst.2010.11.001, 2011.

Kaufman, Y. J., Remer, L. A., Tanre, D., Li, R. R., Kleidman, R., Mattoo, S., Levy, R., Eck, T., Holben, B. N., Ichoku, C., Martins, J., and Koren, I.: A critical examination of the residual cloud contamination and diurnal sampling effects on MODIS estimates of the aerosol over ocean, IEEE T. Geosci. Remote, 43, 28862897, 2005a.

Kaufman, Y. J., Koren I., Remer, L. A., Tanre, D., Ginoux, P., and Fan, S.: Dust transport and deposition observed from the Terra-Moderate Resolution Imaging Spectroradiometer (MODIS) spacecraft over the Atlantic Ocean, J. Geophys. Res., 110, D10S12, doi:10.1029/2003JD004436, 2005b.

King, M. D., Tsay, S. C., Platnick, S. E., Menghua, W., and Liou, K. N.: Cloud retrievals algorithm for MODIS: optical thickness, effective particle radius and thermodynamic phase, Algorithm Theor. Basis Doc. ATBD-MOD-05, NASA Goddard Space Flight Cent., Greenbelt, MD, 1997.

King, M. D., Platnick, S., Menzel, W. P., Ackerman, S. A., and Hubank, P. A.: Spatial and Temporal distribution of clouds observed by MODIS on board the Aqua and Terra Satellites, IEEE T. Geosci. Remote, 51, 3826-3852, 2013.

Leahy, L. V., Wood, R., Charlson, R. J., Hostetler, C. A., Rogers, R. R., Vaughan, M. A., and Winker, D. M.: On the nature and extent of optically thin marine low clouds, J. Geophys. Res., 117, D22201, doi:10.1029/2012JD017929, 2012.

Levy, R. C., Mattoo, S., Munchak, L. A., Remer, L. A., Sayer, A. M., Patadia, F., and Hsu, N. C.: The Collection 6 MODIS aerosol products over land and ocean, Atmos. Meas. Tech., 6, 29893034, doi:10.5194/amt-6-2989-2013, 2013.

Li, Z., Zhao, F., Liu, J., Jiang, M., Zhao, C., and Cribb, M.: Opposite effects of absorbing aerosols on the retrievals of cloud optical depth from spaceborne and ground-based measurements, J. Geophys. Res.-Atmos., 119, 5104-5114, doi:10.1002/2013JD021053, 2014.

Liu, Z., Vaughan, M. A., Winker, D. M., Kittaka, C., Getzewich, B., Kuehn, R., Omar, A., Powell, K., Treptie, C., and Hostetlet, C.: The CALIPSO Lidar Cloud and Aerosol Discrimination: Version 2 Algorithm and Initial Assessment of Performance, J. Atmos. Ocean. Tech., 26, 1198-1213, 2009.

Liu, Z., Winker, D., Omar, A., Vaughan, M., Kar, J., Trepte, C., $\mathrm{Hu}$, Y., and Schuster, G.: Evaluation of CALIOP $532 \mathrm{~nm}$ aerosol optical depth over opaque water clouds, Atmos. Chem. Phys., 15, 1265-1288, doi:10.5194/acp-15-1265-2015, 2015.

Meyer, K., Platnick, S., Oreopoulos, L., and Lee, D.: Estimating the direct radiative effect of absorbing aerosols overlying marine boundary layer clouds in the southeast Atlantic using MODIS and CALIOP, J. Geophys. Res.-Atmos., 118, 48014815, doi:10.1002/jgrd.50449, 2013.

Omar, A. H., Winker, D. M., Tackett, J. L., Giles, D. M., Kar, J., Liu, Z., Vaughan, M. A., Powell, K. A., and Trepte, C. R.: CALIOP and AERONET aerosol optical depth comparisons: One size fits none, J. Geophys. Res.-Atmos., 118, 4748-1766, doi:10.1002/jgrd.50330, 2013.
Peters, K., Quaas, J., and Bellouin, N.: Effects of absorbing aerosols in cloudy skies: a satellite study over the Atlantic Ocean, Atmos. Chem. Phys., 11, 1393-1404, doi:10.5194/acp-11-13932011, 2011.

Remer, L. A., Kaufman, Y. J., Tanre, D., Mattoo, S., Chu, D. A., Martins, J. V., Li, R. R., Ichoku, C., Levy, R. C., Kleidman, R. G., Eck, T. F., Vermote, E., and Holben, B. N.: The MODIS aerosol algorithm, products and validation. J. Atmos. Sci., 62, 947-973, 2005.

Roberts, G., Wooster, M. J., and Lagoudakis, E.: Annual and diurnal african biomass burning temporal dynamics, Biogeosciences, 6 , 849-866, doi:10.5194/bg-6-849-2009, 2009.

Rossow, W. B. and Schiffer, R. A.: Advances in understanding clouds from ISCCP, B. Am. Meteorol. Soc., 80, 2261-2287, 1999.

Royal Netherlands Meteorological Society: Background information about Row Anomaly in OMI, available at: www.knmi.nl/ omi/research/product/rowanomaly-background.php, last access: 22 December 2014

Sassen, K. and Cho, B. S.: Subvisual-thin cirrus lidar dataset for satellite verification and climatological research, J. Appl. Meteorol., 31, 1275-1285, 1992.

Satheesh, S. K., Morthy, K. K., Kaufman, Y. J., and Takemura, T.: Aerosol optical depth, physical properties and radiative forcing over the Arabian Sea, Meterol. Atmos. Phys., 91, 45-62, 2006.

Sayer, A. M., Hsu, N. C., Bettenhausen, C., Ahmad, Z., Holben, B. N., Smirnov, A., Thomas, G. E., and Zhang, J.: SeaWiFS Ocean Aerosol Retrievals (SOAR): algorithm, validation, and comparison with other datasets, J. Geophys. Res., 117, D03206, doi:10.1029/2011JD016599, 2012.

Schrage, J. M. and Fink, A. H.: Nocturnal continental low-level stratus over Tropical West Africa: observations and possible mechanisms controlling its onset, Mon. Weather Rev., 140, 1794-1809, doi:10.1175/MWR-D-11-00172.1, 2012.

Shi, Y., Zhang, J., Reid, J. S., Holben, B., Hyer, E. J., and Curtis, C.: An analysis of the collection 5 MODIS over-ocean aerosol optical depth product for its implication in aerosol assimilation, Atmos. Chem. Phys., 11, 557-565, doi:10.5194/acp-11-557-2011, 2011.

Smirnov, A., Holben, B. N., Giles, D. M., Slutsker, I., O’Neill, N. T., Eck, T. F., Macke, A., Croot, P., Courcoux, Y., Sakerin, S. M., Smyth, T. J., Zielinski, T., Zibordi, G., Goes, J. I., Harvey, M. J., Quinn, P. K., Nelson, N. B., Radionov, V. F., Duarte, C. M., Losno, R., Sciare, J., Voss, K. J., Kinne, S., Nalli, N. R., Joseph, E., Krishna Moorthy, K., Covert, D. S., Gulev, S. K., Milinevsky, G., Larouche, P., Belanger, S., Horne, E., Chin, M., Remer, L. A., Kahn, R. A., Reid, J. S., Schulz, M., Heald, C. L., Zhang, J., Lapina, K., Kleidman, R. G., Griesfeller, J., Gaitley, B. J., Tan, Q., and Diehl, T. L.: Maritime aerosol network as a component of AERONET - first results and comparison with global aerosol models and satellite retrievals, Atmos. Meas. Tech., 4, 583-597, doi:10.5194/amt-4-583-2011, 2011.

Stephens, G. L., Vane, D. G., Boain, R. J., Mace, G. G., Sassen, K., Wang, Z., Illingsworth, A. J., O'Connor, E. J., Rossow, W. B., Durden, S. L., Miller, S. D., Austin, R. T., Benedetti, A., and Mitrescu, C.: The Cloudsat mission and the A-Train, B. Am. Meteorol. Soc., 83, 1771-1790, doi:10.1175/BAMS-83-121771, 2002. 
Thomason, L. W., Pitts, M. C., and Winker, D. M.: CALIPSO observations of stratospheric aerosols: a preliminary assessment, Atmos. Chem. Phys., 7, 5283-5290, doi:10.5194/acp-7-5283-2007, 2007.

Torres, O., Tanskanen, A., Viehelmann, B., Ahn, C., Braak, R., Bhartia, P. K., Veefkind, P., and Levelt, P.: Aerosols and surface UV products from Ozone Monitoring observations: an overview, J. Geophys. Res., 112, D24S47, doi:10.1029/2007JD008809, 2007.

Torres, O., Jethva, H., and Bhartia, P. K.: Retrieval of aerosol optical depth above clouds from OMI observations: sensitivity analysis and case studies. J. Atmos. Sci., 69, 1037-1053, 2012.

Toth, T. D., Zhang, J., Campbell, J. R., Reid J. S., Shi, Y., Johnson, R. S., Smirnov, A., Vaughan, M. A., and Winker, D. M.: Investigating enhanced Aqua MODIS aerosol optical depth retrievals over the mid-to-high latitude Southern Oceans through intercomparison with co-located CALIOP, MAN, and AERONET data sets, J. Geophys. Res. Atmos., 118, 4700-4714, doi:10.1002/jgrd.50311, 2013.

Vaughan, M. A., Powell K. A., Kuehn, R. E., Young, S. A., Winker, D. M., Hostetler C. A., Hunt W. H., Liu, Z., McGill, M. J., and Getzewich, B. J.: Fully automated detection of cloud and aerosol layers in the CALIPSO lidar measurements, J. Atmos. Ocean. Tech., 26, 2034-2050, 2009.

Weatherhead, E. C., Reinsel, G. C., Tiao, G. C., Meng, X. L., Choi, D., Cheang, W. K., Keller, T., DeLuisi, J., Wuebbles, D. J., Kerr, J. B., Miller, A. J., Oltmans, S. J., and Frederick, J. E.: Factors affecting the detection of trends: statistical considerations and applications to environmental data, J. Geophys. Res., 103, 1714917161, 1998.

Wilcox, E. M.: Direct and semi-direct radiative forcing of smoke aerosols over clouds, Atmos. Chem. Phys., 12, 139-149, doi:10.5194/acp-12-139-2012, 2012.

Wilcox, E. M., Harshvardian and Platnick, S.: Estimate of the impact of absorbing aerosol over cloud on the MODIS retrievals of cloud optical thickness and effective radius using two independent retrievals of liquid water path, J. Geophys. Res., 114, D05210, doi:10.1029/2008JD010589, 2009.

Winker, D. M., Vaughan, M. A., Omar, A. H., Hu, Y., Powell, K. A., Liu, Z., Hunt, W. H., and Young, S. A.: Overview of the CALIPSO mission and CALIOP data processing Algorithm. J. Atmos. Ocean. Tech., 26, 2310-2323, doi:10.1175/2009JTECHA1281.1, 2009.
Winker, D. M., Pelon, J., Coakley Jr., J. A., Ackerman, S. A., Charlson, R. J., Colarco, P. R., Flamant, P., Fu, Q., Hoff, R. M., Kittaka, C., Kubar, T. L., Le Treut, H., McMormick, M. P., Megie, G., Poole, K., Powell, K., Trepte, C., Vaughan, M. A., and Wielicki, B. A. :The CALIPSO mission: a global 3d view of aerosols and clouds, B. Am. Meteorol. Soc., 91, 1211-1229, doi:10.1175/2010BAMS3009.1, 2010.

Wood, R.: Stratocumulus clouds, Mon. Weather Rev., 140, 2373 2423, 2012.

Yu, H., Dickinson, R., Chin, M., Kaufman, Y., Holben, B., Geogdzhayev, I., and Mischenko, M.: Annual cycle of global distributions of aerosol optical depth from integration of MODIS retrievals and GOCART model simulations, J. Geophys. Res., 108, 4128, doi:10.1029/2002JD002717, 2003.

Yu, H., Zhang, Y., Chin, H., Liu, Z., Omar, A., Remer, L. A., Yang, Y., Yuan, T., and Zhang, J.: An integrated analysis of aerosols above-clouds from A-train multi sensor measurements, Remote Sens. Environ., 121, 125-131, 2012.

Zhang, J. and Reid, J. S.: MODIS aerosol product analysis for data assimilation: assessment of level 2 aerosol optical thickness retrievals, J. Geophys. Res., 111, D222077, doi:10.1029/2005JD006898, 2006.

Zhang, J. and Reid, J. S.: A decadal regional and global trend analysis of the aerosol optical depth using a data-assimilation grade over-water MODIS and Level 2 MISR aerosol products, Atmos. Chem. Phys., 10, 10949-10963, doi:10.5194/acp-1010949-2010, 2010.

Zhang, J., Christopher, S. A., and Holben, B. N.: Intercomparison of smoke aerosol optical thickness derived from GOES 8 imager and ground-based Sun photometers, J. Geophys. Res., 106, 7387-7397, doi:10.1029/2000JD900540, 2001.

Zhang, J., Campbell, J. R., Reid, J. S., Westphal, D. L., Baker, N. L., Campbell, W. F., and Hyer, E. J.: Evaluating the impact of assimilating CALIOP-derived aerosol extinction profiles on a global mass transport model, Geophys. Res. Lett., 38, L14801, doi:10.1029/2011GL047737, 2011.

Zhang, J., Reid, J. S., Campbell, J. R., Hyer, E. J., and Westphal, D. L.: Evaluating the impact of multi-sensor data assimilation on a global aerosol particle transport model, J. Geophys. Res.-Atmos., 119, 4674-4689, doi:10.1002/2013JD020975, 2014. 